\title{
Structural and Vibrational Study of Molecular Interaction in a Ternary Liquid Mixture of Benzylamine, Ethanol and Benzene
}

Hema .

M. B. govt. P. G. College Haldwani

Tara Bhatt ( $\square$ tarabhatt0511@gmail.com )

M. B. GOVT. P. G. COLLEGE HALDWANI https://orcid.org/0000-0002-8922-7863

Pratibha Arya

M. B. govt. P. G. College Haldwani

Charu Ch. Dhondiyal

M. B. govt. P. G. College Haldwani

Himani Tiwari

M. B. govt. P. G. College Haldwani

Kamal Devlal

M. B. govt. P. G. College Haldwani

\section{Research Article}

Keywords: Conventional and non-conventional H-bonding, DFT, Non-covalent interaction, FTIR

Posted Date: July 7th, 2021

DOl: https://doi.org/10.21203/rs.3.rs-649250/v1

License: (c) (i) This work is licensed under a Creative Commons Attribution 4.0 International License. Read Full License 


\section{Abstract}

The structural study of the non-covalent interactions in the ternary mixture of benzylamine (BA), ethanol and benzene have been attempted through Density Functional Theory (DFT) calculation. The optimized structure of monomers (BA, ethanol and benzene), BA dimer and their complexes (BA-benzene, BA-ethanol, BA-ethanol-benzene) and their interaction energy is used to describe the intermolecular interaction between the molecules. In addition to conventional $\mathrm{H}$-bonding, the stability of the system is found to depend on several other interactions such as $\mathrm{CH} / \pi, \mathrm{NH} / \pi, \mathrm{OH} / \pi$ interaction. The Fourier Transform InfraRed (FTIR) spectroscopy technique is also used to study molecular interaction. An interpretation of the IR stretching bands based on the interactions is also provided. The variation in IR band position and intensity of spectra with change in concentration of the mixture shows that different kinds of interactions are presented in the mixture. The strength of these interactions varies with concentration. At lower concentration $\left(x_{1}=0.0\right)$, weak $\mathrm{OH} / \pi$ interaction between benzene and ethanol takes place while at other mole fraction $\mathrm{N}-\mathrm{H}--\mathrm{O}, \mathrm{O}-\mathrm{H}--\mathrm{N}$, $\mathrm{NH} / \pi$ interaction is present between molecules.

\section{Introduction}

The widespread uses of amine[1] and the presence of the amine group in many compounds of biological interest, make it an interesting functional group. Benzylamine is used in pharmaceutical industries in the preparation of several drugs. It is also used to manufacture explosives and also used as propellant in rockets and missiles[2]. There are several studies done on the binary liquid mixture comprising primary amine, secondary amine, tertiary amine and cyclic amine with aromatic hydrocarbon, alcohol, non-ionic solvents and cyclic ether[3-7].

In view of the importance of mixture of BA with other organic compounds and to engineer the properties of such mixture, the knowledge of intermolecular interaction is a must. Also, the intermolecular interaction predominantly controls the molecular mechanism of the substance and its understanding helps in the improvement of the properties of the system[8]. In the present investigation, the molecular interaction study of BA with aromatic substance in the polar environment is undertaken via theoretical quantum chemical calculation and experimental FTIR spectroscopy.

The quantum chemical calculation helps to understand the molecular geometry and the electronic properties at atomic level. It can directly provide the intrinsic strength and geometrical preferences of interactions as found in small model systems. These calculations can also determine the relative importance of the fundamental forces that make up the interactions like electrostatic, induction, dispersion, and exchange-repulsion forces and tell about the nature of the interaction[9-11].

In conjugation with theoretical calculation, vibrational spectroscopy also has the potential to yield valuable structural and conformational information of organic compounds. The analysis of vibrational frequencies shift, change in spectral band shape and intensity upon changing environment provides the information about the intermolecular interactions. The absorption peak is usually sharper in the IR spectrum and so, it is exceptionally sensitive to change in bond strength and even a small change of $0.02 \%$ can be easily 
detected by it $[12,13]$. The sensitivity of IR spectroscopy towards a small change makes it a good tool to investigate the structure and molecular interaction in the last several decades[14-17].

In the liquid medium, vibrational relaxation band and rotational motion band mixing make the analysis of the IR band complicated. For analysing the spectra with overlapping bands, the Fourier self-deconvolution method $[18,19]$ is used. The concept of deconvolution assumes that a spectrum of the single band is broadened in a liquid mixture due to molecular interaction.

In the present work, the structures of monomers (benzylamine (BA), ethanol and benzene), BA dimer and their complexes (BA-benzene, BA-ethanol, BA-ethanol-benzene) have been optimized using density functional theory with B3LYP functional. The geometry optimization gives the bond parameters and dipole moment which are a good source of information related to non-bonded interactions. DFT with wB97X-D functional has been used to calculate interaction energy because it includes the dispersive interaction. All the computations were done with DFT with a basis set of $6-311++G^{\star \star}$. The vibrational analysis of the mixture by FTIR (Fourier Transformed InfraRed Spectroscopy) is used to get the detailed description of structural modification and intermolecular interaction on mixing the liquids.

\section{Experimental And Methods 2.1. Experimental}

The chemicals, benzene and benzylamine were purchased from SRL India and ethanol was purchased from MERCK. All chemicals were of minimum assay of $99.9 \%$ and used without further purification. The mixture of different mole fractions was prepared by mass. The weighing was done using a digital balance of accuracy $\pm 1 \mathrm{mg}$. The mole fraction of the second compound i.e. ethanol was kept fixed at 0.4 while the mole fraction of the other two ( $x_{1}$ of benzylamine and $x_{3}$ of benzene) varied from 0.0 to 0.6 to have the mixtures of various mole fraction.

The FTIR (Fourier Transformed InfraRed) spectra of pure components and their mixture at different concentrations were recorded in transmission mode. Samples were scanned using "Spectrum Two ${ }^{\mathrm{TM}}$ FTIR spectrophotometer (PerkinElmer)" equipped with deuterated triglycine sulfate (DTGS) detector and potassium bromide $(\mathrm{KBr})$ as a beam splitter. The instrument was connected to Spectrum $10 \mathrm{ES}^{\mathrm{TW}}$ software and spectra were scanned at wavenumbers of $4000-400 \mathrm{~cm}^{-1}$, at a resolution of $2 \mathrm{~cm}^{-1}$ and room temperature $\otimes 293 \mathrm{~K}$.

\section{Decomposition of spectra:}

The decomposition was performed by using a fitting algorithm implemented in Origin 2018. The number of Gaussian peaks were varied from one to ten. The individual components of the deconvolved spectra were determined by an iterative curve-fitting procedure that assumed Gaussian band envelopes for the deconvolved components. In this procedure, the peak position, the intensity and the width were taken as the fitting parameter. 


\subsection{Computational}

The possible interactions between like and unlike molecules were investigated by quantum chemical calculation. The study of the dimer of benzylamine (BA) and the complex of BA, ethanol and benzene were optimized in the gas phase and their interaction energies were calculated. The common practice of running a high-level single point energy calculation on the geometry computed by the use of a cheaper method is as effective as performing all calculations at a higher level of theory [20]. The calculations were performed at the DFT/6-311 ++G(d,p) level using the GAMESS program [21] at the web-based interface facility www.chemcompute.org [22]. The geometry is optimized by B3LYP functional while single point energy on optimized geometry was calculated with wb97X-D functional. The wB97X-D functional include empirical atom-atom dispersion corrections and is significantly superior for non-bonded interactions. It yields satisfactory accuracy for thermochemistry, kinetics and non-covalent interactions [23]. The interaction energies were determined by using the "Supermolecular" method [24].

\section{Results And Discussion}

\subsection{Theoretical: Geometries and Noncovalent Interactions.}

Fig.1-Fig.6 are the optimized geometries of molecules, BA dimer and their complexes. The optimized geometry of benzene and ethanol was taken from Hema at al[25]. It helps in establishing relationships among molecular structure and intermolecular interactions. Single point energy, interaction energy and dipole moment are summarised in Table 1.

The interaction between structural subunits modifies the bond length, bond angle or leads to some preferred geometry which is the most fundamental source to understand the intermolecular interaction between molecules. The possible interaction between molecules based on structural changes and interaction energies are discussed as:

Benzylamine (BA) (Fig.1) is a polar molecule (Table 1) and can interact with any polar molecule as well as non-polar molecules. BA molecules have a $\pi$-ring ( $\pi$-plane) which interacts with $\mathrm{H}$-doner molecules. Since such interaction is a plane-to-point kind of interaction, there could be more than one possible conformation geometries.

On dimerization of BA, either the $\mathrm{NH}_{2}$ group of BA molecules interact via $\mathrm{H}$-bonding (Fig.2) or the $\mathrm{N}-\mathrm{H}$ bond of one molecule takes a perpendicular position above the plane of $\pi$-ring of another molecule (Fig.3), with interaction energy -7.795 and $-7.117 \mathrm{Kcal} / \mathrm{mol}$ respectively. In the $\mathrm{H}$-bonding case, the bond length $\mathrm{r}(\mathrm{C}-\mathrm{N})$ of the doner BA molecule gets increased by $0.005 \AA$ while $\mathrm{r}(\mathrm{N}-\mathrm{H})$ of the acceptor gets increased by $0.004 \AA$. In plane-to-point kind of interaction, the interaction distance between the $\mathrm{N}-\mathrm{H}$ bond and $\pi$-ring of two $\mathrm{BA}$ molecules are $2.903 \AA$ and $3.066 \AA$. Which is slightly higher than the $\mathrm{Hp} / \pi$ interaction distance of 2.635 $\AA[25]$. The $\mathrm{N}-\mathrm{H}$ bond perpendicular to the $\pi$-ring get elongated as a result of interaction between two $\mathrm{BA}$ molecules. Hussain et al[7] also reported that BA dimer is stabilized by $\mathrm{NH} / \pi$ and $\mathrm{N}-\mathrm{H}--\mathrm{O}$ type of molecular interactions. 
$\mathrm{BA}$ and ethanol both are polar molecules and are capable of forming $\mathrm{H}$-bond. As $\mathrm{N}-\mathrm{H}-\mathrm{O}$ hydrogen bond is stronger than $\mathrm{O}-\mathrm{-H}-\mathrm{N}$ hydrogen bond, it is expected that when BA-ethanol complex is formed (Fig.4), then they will interact via N--H-O bond (K.V. Zaitseva et al. [26] reported that aliphatic amines dissolved in methanol form $\mathrm{O}-\mathrm{H}$.... N type $\mathrm{H}$-bonding.). But $\pi$-ring of BA provides better stability to the $\mathrm{O}-\mathrm{H}$ bond of ethanol, therefore, the $\mathrm{O}-\mathrm{H}$ bond of ethanol takes a geometry perpendicular to $\pi$-ring at $2.930 \AA$. The $\mathrm{CH}_{2}$ group of BA provides flexibility to the $\mathrm{N}-\mathrm{H}$ bond and so it interacts with ethanol via $\mathrm{O}-\mathrm{-H}-\mathrm{N}$ hydrogen bonding with interaction energy $-4.461 \mathrm{Kcal} / \mathrm{mol}$ and interaction length $2.220 \AA$. On clustering of $B A$ and ethanol, the bond length of ethanol $\mathrm{r}(\mathrm{O}-\mathrm{H})$ increases by $0.004 \AA$ and $\mathrm{r}(\mathrm{O}-\mathrm{C})$ increases by $0.006 \AA$ while the bond length of $\mathrm{BA} r(\mathrm{~N}-\mathrm{H})$ increases by $0.004 \AA$ and $\mathrm{r}(\mathrm{C}-\mathrm{N})$ decreases by $0.008 \AA$.

The interaction between benzene and BA (Fig.5), results in geometry such that, the N-H bond of BA takes position perpendicular to $\pi$-ring of benzene at a distance of $3.056 \AA$. The dispersive forces between the $\pi-\pi$ ring of benzene and BA cause the interaction of two $\pi$-rings in such a way that the two $\pi$-rings, one of benzene and other of BA, takes T-shape similar to benzene dimer (T-shape structure [25]) and the bond length $\mathrm{r}(\mathrm{C}-\mathrm{H})$ of benzene gets decreased by $0.001 \AA$. Hobza et al [27] reported a similar kind of interaction between a $\mathrm{C}-\mathrm{H}$ donor and a $\pi$-face of an aromatic moiety and characterized it by a shortening of the $\mathrm{C}-\mathrm{H}$ bond length and a blue shift of the $\mathrm{C}-\mathrm{H}$ stretching frequency and called it $\mathrm{C}-\mathrm{H} \ldots \pi$ interaction. The distance of the $\mathrm{C}-\mathrm{H}$ bond of benzene and centre of $\pi$-ring of $\mathrm{BA}$ is $3.464 \AA$ (larger than what is predicted by MP2 level theory 2.252 to $2.770 \AA$ as a study by Kumar et al[28] for adamantane-benzene complexes because the DFT method does not include the dispersive forces). So, the BA-benzene cluster is stabilized by two interactions, $\mathrm{NH} / \pi$ interaction and $\mathrm{CH} / \pi$ interaction with interaction energy $-4.954 \mathrm{Kcal} / \mathrm{mol}$.

In BA-ethanol-benzene complex (Fig.6), the complex is stabilized by a different kind of interaction such as $\mathrm{NH} / \pi$ interaction between BA-benzene, $\mathrm{O}-\mathrm{H} \ldots . . . . \mathrm{N}$ hydrogen bonding between BA-ethanol complex. The interaction energy of this complex is $-13.36 \mathrm{Kcal} / \mathrm{mol}$.

The intermolecular interactions are: (1) between $\mathrm{BA}$ dimer: $\mathrm{NH} / \pi$ and $\mathrm{N}-\mathrm{H}--\mathrm{O}$ type $\mathrm{H}$-bonding interaction, (2) between benzene and $\mathrm{BA}: \mathrm{NH} / \pi$ and $\mathrm{CH} / \pi$ and (3) between ethanol and $\mathrm{BA}: \mathrm{Hp} / \pi$ and $\mathrm{H}$-bonding. The space between benzene and benzylamine molecule is the largest.

\subsection{FTIR spectral analysis:}

FT-IR spectroscopy is a suitable technique to investigate the intermolecular interaction. The interaction between the different molecules leads to the formation of the new vibrational degree of freedom which appears at shifted frequencies. So, the vibrational frequency shifts, changes of shape and intensity of IR absorption peaks resulting from some characteristic functional groups can be attributed to the existence of intermolecular interaction. [29,30]

The IR absorption bands are caused by changes between different vibrational states of bonds in molecules. Vibrational transitions can most easily be discussed based on a harmonic oscillator model in which Hooke's Law holds at least approximately. Using Hooke's law, the vibrational frequency of a 
chemical bond, where atoms and the connecting bond are modelled as a simple harmonic oscillator, is [31]-

$$
v=\frac{1}{2 \pi} \sqrt{\frac{\mathrm{k}}{\mathrm{m}}}
$$

Where $\mathrm{k}$ is force constant.

Within the Harmonic approximation, the IR absorption coefficient per unit length of a sample of volume $\mathrm{V}$ is[32, 33]

$$
\alpha(\omega) n(\omega)=\frac{2 \pi \omega^{2} \beta}{3 c V} \int_{-\infty}^{\infty}\left\langle\sum \mu_{i}(t) \cdot \mu_{j}(0)\right\rangle e^{-i \omega t} d t
$$

Where $n(\omega)$ is the refractive index and $\beta=\frac{1}{K_{B} T}$

The intensity of absorption depends on the molecular dipole moment .

The frequency range of an IR absorption band, at which a given bond absorbs, depends on the strength of the bond and the masses that make the bond. According to Beer's - Lambert's law the increasing concentration of solution and increase in path length affect the intensity of the IR absorption band [34]. So, the absorbance of a band is influenced by the number of molecules which undergo a change in their vibrational states upon absorption of IR radiation and the bond dipole moment.

Band assignment: The spectrum is evaluated by assigning vibrational peaks to different functional groups. In Table 2 the spectral peak and vibrational bands of pure components that were taken from the literature [35-38] are presented.

The experimental FTIR spectra of the mixture at different concentrations and of pure components (Fig.7) is a complicated one. So, the discussion of different frequency range depending upon the major vibrational bands is as follows:

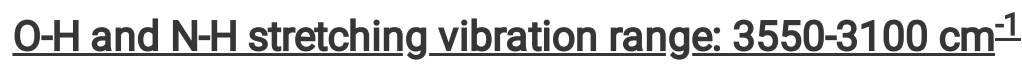

The measurement of the $\mathrm{X}-\mathrm{H}$ stretching frequencies can be a preferred tool to investigate $\mathrm{H}$-bond in $\mathrm{X}-\mathrm{H}-$ $\mathrm{Y}$ system. According to Arunan et al [39], the greater the lengthening of the $\mathrm{X}-\mathrm{H}$ bond in the $\mathrm{X}-\mathrm{H}-\mathrm{-}-\mathrm{Y}$ system, the stronger and shorter is the $\mathrm{H}---\mathrm{Y}$ hydrogen bond and vice versa. $\mathrm{H}--\mathrm{Y}$ hydrogen bond length also depends on the bond angle.

Both $\mathrm{N}-\mathrm{H}$ and $\mathrm{O}-\mathrm{H}$ stretching vibration lies in the spectral range $3550-3100 \mathrm{~cm}^{-1}$ (Fig.8). The $0-\mathrm{H}$ stretching vibration in ethanol shows a peak at $3308.63 \mathrm{~cm}^{-1}$ with transmittance $75.97 \%$ while N-H stretching vibration in benzylamine show two peaks at $3371.10 \mathrm{~cm}^{-1}$ and $3284.83 \mathrm{~cm}^{-1}$ corresponding to symmetric 
and asymmetric (higher frequency) vibration. Benzene does not show any peak in this region. For $\mathrm{x}_{1}=0.0$, the peak is at $3324.93 \mathrm{~cm}^{-1}$ with increased transmittance to $90.57 \%$. There is a shift of $16.30 \mathrm{~cm}^{-1}$ toward a higher wavenumber. When benzene and ethanol are mixed, the $\mathrm{H}$-bonding between ethanol molecules ruptures and the $\mathrm{OH} / \pi$ interaction between benzene and ethanol takes place. The shift in $\mathrm{O}-\mathrm{H}$ stretching vibration wavenumber towards higher wavenumber shows that the $\mathrm{O}-\mathrm{H}$ bond length of $\mathrm{H}$-bonded ethanol (such as ethanol dimer) gets decreased on interacting with benzene via $\mathrm{OH} / \pi$ interaction and that the strength of $\mathrm{OH} / \pi$ interaction is weak compared to conventional $\mathrm{H}$-bonding of ethanol. It is a wellestablished fact that the formation of hydrogen bonding lowers the frequency of $\mathrm{OH}$ stretching vibration and a broader band appears at a lower frequency as compared to the free $\mathrm{OH}$ group. This gives a sharp band in the frequency range of $3650-3590 \mathrm{~cm}^{-1}$ [40]. The intensity of O-H stretching vibration get decreased at 0.0 mole fraction because compared to pure ethanol, a smaller number of ethanol molecules are present to absorb the radiation corresponding to $\mathrm{O}-\mathrm{H}$ stretching vibration in the benzene-ethanol mixture. Previous, theoretical interaction energies also show that the $\mathrm{OH} / \pi$ interaction is weaker than $\mathrm{H}$ bonding [25].

After 0.0 i.e. when BA is introduced in the mixture, the spectra become complex because $\mathrm{O}-\mathrm{H}$ and $\mathrm{N}-\mathrm{H}$ absorb in the same frequency range, but the $\mathrm{N}-\mathrm{H}$ band is sharper and of lower intensity. The change in shape and shift in wavenumber take place with increasing concentration of BA. From Table 3, the respective peak position of $\mathrm{N}-\mathrm{H}$ symmetric, $\mathrm{N}-\mathrm{H}$ asymmetric and $\mathrm{O}-\mathrm{H}$ stretching vibrations gets shifted. At $\mathrm{x}_{1}=0.6$, the main peak of $\mathrm{N}-\mathrm{H}$ stretching vibration gets shifted towards lower wavenumber i.e. shows redshift compared to the peak position in BA. This indicates that the $\mathrm{N}-\mathrm{H}$ bond length gets increased in the BA-ethanol mixture as compared to pure BA. This results in an overall decrease in $\mathrm{NH}$ stretching vibration frequency.

At $x_{1}=0.6$ (Fig.9), the deconvolution of the spectra shows that the peak in the $3500-3100 \mathrm{~cm}^{-1}$ is made of five components. One is due to $\mathrm{O}-\mathrm{H}$ stretching $\left(3360 \mathrm{~cm}^{-1}\right)$, the second and third due to $\mathrm{N}-\mathrm{H}$ symmetric and asymmetric stretching $\left(3361.23 \mathrm{~cm}^{-1}\right.$ and $\left.3287.07 \mathrm{~cm}^{-1}\right)$ and as the hydrogen bonding creates an additional relaxation channel, so the other two will be due to the interaction present in the mixture between different components such as $\mathrm{OH} / \pi$ and $\mathrm{N}-\mathrm{H}--\mathrm{O}$ interactions. Also, on mixing ethanol and $\mathrm{BA}, \mathrm{N}-\mathrm{H}$ stretching frequency gets red-shifted (Rajpurohit et al [41] show that $\mathrm{N}-\mathrm{H}---\mathrm{O}$ bonding shows a red-shift in amino group frequency.) while $\mathrm{O}-\mathrm{H}$ stretching frequency gets blue shifted. This indicates that the strength of the interaction in the BA-eth mixture is weaker than that of pure ethanol but stronger than the interaction in pure BA interaction. On analysing the components of the deconvoluted spectrum, it is seen that on mixing ethanol and $\mathrm{BA}$, the $\mathrm{O}-\mathrm{H}$ stretching frequency get more affected compared to $\mathrm{N}-\mathrm{H}$ vibration frequency indicating that in BA-ethanol mixture $\mathrm{O}-\mathrm{H}-\mathrm{N}$ hydrogen bonding dominates over the $\mathrm{N}-\mathrm{H}-\mathrm{O}$ hydrogen bonding (Similar to aliphatic amine and alcohol mixture as reported by Zaitseva et al. [26]). Although, in the mixture both $\mathrm{O}-\mathrm{H}--\mathrm{N}$ and $\mathrm{N}-\mathrm{H}--\mathrm{O}$ hydrogen bonding will be present. Theoretical results also predict the $\mathrm{N}-\mathrm{H}-\mathrm{O}$ type hydrogen bonding in the BA-ethanol complex.

But with mole fraction, the intensity and wavenumber both do not follow a particular pattern because in a mixture the extent of interaction of each molecule with the other is different. The concentration of the 
mixture and relative strength of interactions are the key factor to decide the IR spectra of the mixture.

\section{C-H stretching Vibration: $3100-2900 \mathrm{~cm}^{-1}$}

The C-H stretching vibrations of ethanol, BA and benzene fall in the wavenumber range $3100-2900 \mathrm{~cm}^{-1}$ (Fig.10). For Benzene the peak is at $3035.86 \mathrm{~cm}^{-1}$. BA shows two $\mathrm{C}-\mathrm{H}$ stretching vibration bands at $3026.06 \& 2911.54 \mathrm{~cm}^{-1}$ due to the aromatic $\mathrm{C}-\mathrm{H}$ and $\mathrm{CH}_{2}$ groups. Ethanol also shows two $\mathrm{C}-\mathrm{H}$ stretching bands at 2973.24 and $2928.46 \mathrm{~cm}^{-1}$ due to $\mathrm{CH}_{2}$ and $\mathrm{CH}_{3}$ group (Table 4).

In aromatic $\mathrm{C}-\mathrm{H}$ stretching vibration, the stabilization of $\pi-\pi$ interaction in the polar environment (Diederich et al [8] reported that the strong $\pi-\pi$ interaction in the polar solvent.) leads to the shortening of $\mathrm{C}-\mathrm{H}$ bond length and causes an increase in aromatic $\mathrm{C}-\mathrm{H}$ vibration frequency. This kind of vibrational frequency increase is also observed for ethanol- benzene at 0.0 mole fraction and BA-ethanol at 0.6 mole fraction. The increased polarity of solvent reduces the transition dipole moment of $\mathrm{C}-\mathrm{H}$ vibration [42]. This will cause a fall in the intensity of $\mathrm{C}-\mathrm{H}$ vibration with increasing $\mathrm{x}_{1}$. The $\mathrm{C}-\mathrm{H}$ stretching vibration frequency of ethanol gets decreased when it gets mixed with benzene $\left(x_{1}=0.0\right)$, indicating that the $\mathrm{C}-\mathrm{H}$ bond length in the mixture gets decreased compared to $\mathrm{H}$-bonded ethanol solvent. The increased amount of red-shift with mole fraction (Table 4) indicates the weakening of the $\mathrm{C}-\mathrm{H}$ bond of ethanol.

When the scale in the wavelength range $3010-3045 \mathrm{~cm}^{-1}$ is expanded, it is observed that at various mole fractions (Fig.11), the aromatic C-H stretching vibration is found to be the combination of two aromatic C$\mathrm{H}$ vibrations, one of benzene and other of $\mathrm{BA}$. At lower mole fraction it is mainly due to benzene, with increasing mole fraction, the contribution of BA increases and at higher concentration, it is due to BA. At mid mole fraction, such as 0.3 the deconvolution of the band shows that the $\mathrm{C}-\mathrm{H}$ vibration is due to benzene, BA, and the interaction between them (Fig.12).

\section{Aromatic C-C stretching and $\mathrm{NH}_{2}$ bending Vibration: $1700-1550 \mathrm{~cm}^{-1}$}

The mix band with peak at $1604.36 \mathrm{~cm}^{-1}$ and $1584.65 \mathrm{~cm}^{-1}$ corresponds to $\mathrm{NH}_{2}$ bending and aromatic $\mathrm{C}-\mathrm{C}$ stretch of BA (Fig.13). The position of bands does not shift too much but their transmission gets decreased with increasing mole fraction. More the mole fraction, more BA molecule will be available to absorb the vibration.

\section{Aromatic C-C stretching Vibration of benzene: $1465-1490 \mathrm{~cm}^{-1}$}

The aromatic C-C vibration of benzene shows a peak at $1478.24 \mathrm{~cm}^{-1}$ with a transmittance of $80.26 \%$ (Fig.14) and shows a small shift toward a higher wavenumber with an increasing mole fraction (Table 5). The absorption intensity of IR spectra depends on molecular dipole moment[32, 33], so, the increased intensity of aromatic $\mathrm{C}-\mathrm{C}$ stretching at 0.0 mole fraction represents that the molecular dipole moment gets increased in a polar (ethanol) environment. Polarizability is an important consideration for aromatic molecules for their interaction [43]. This increased molecular dipole moment in polar solvent leads to strong $\pi-\pi$ interaction as reported by Diederich et al [8]. With further increase in mole fraction, the 
decreasing intensity is due to a decrease in benzene concentration. The strong $\pi-\pi$ interaction leads to stabilization of $\pi$-ring which leads to a blue shift in absorption frequency. A similar observation of blue shift of ring C-C stretching frequency is reported by Li et al [44] for pyridine+ water complex.

\section{C-N stretching vibration of BA and C-O stretching vibration of ethanol: $1070-1020 \mathrm{~cm}^{-1}$}

The effect in the stretching frequency of $\mathrm{C}-\mathrm{N}$ and $\mathrm{C}-\mathrm{O}$ is due to the redistribution of electron density of molecules taking part in intermolecular interaction. This leads to variation in the bond length of the nearest neighbour of the atom that takes part in the interaction with other molecules as seen in theoretical calculation of optimized geometries.

From Fig. 15, the position of the $\mathrm{C}-0$ stretching frequency of ethanol is $1046.03 \mathrm{~cm}^{-1}$. For all concentrations, the wavenumber of $\mathrm{C}-\mathrm{O}$ stretching frequency gets increased compared to ethanol because, in all interactions involving ethanol (such as $\mathrm{OH} / \pi$ or $\mathrm{N}-\mathrm{H}--\mathrm{O}$ ) the $\mathrm{C}-\mathrm{O}$ bond length gets increased. With increasing mole fraction, the $\mathrm{C}-\mathrm{O}$ stretching frequency gets shifted towards a higher wavenumber. This is due to variation in the strength of interaction.

As we move from 0.0 to 0.1 mole fraction, the change in interaction from weak $\mathrm{OH} / \pi$ to strong $\mathrm{H}$-bonding takes place which shows a considerable shift in frequency (from 1048 to $1049 \mathrm{~cm}^{-1}$ ). However, when the mole fraction is above 0.2 , the nature of the interaction is the same so almost no shift in wavenumber is observed. The transmittance is the same for all mole fractions because the mole fraction of ethanol is fixed at all concentrations.

The C-N stretching vibrational band appears at $1025.41 \mathrm{~cm}^{-1}$ with a transmittance of $85.32 \%$. The C-N stretching vibration disappears at a lower mole fraction (lower than 0.5 ).

\section{Conclusion}

In the present investigation, the presence of various types of interactions between benzylamine (BA), ethanol and benzene were established using DFT investigation of the geometrical parameters and energetics. The optimized structure of the BA dimer shows that BA is self-associated through conventional $\mathrm{H}$-bonding and $\mathrm{NH} / \pi$ interaction. The BA-B structure is a delicate balance of $\mathrm{NH} / \pi$ and $\mathrm{CH} / \pi$ interaction and in BA-ethanol complex $\mathrm{N}-\mathrm{H}--\mathrm{O}$ hydrogen bonding and $\mathrm{OH} / \pi$ interactions are present. FTIR technique is used to study the structural changes and intermolecular interactions. A blue shift in $\mathrm{O}-\mathrm{H}$ stretching frequency indicates the presence of $\mathrm{OH} / \pi$ interactions between benzene and ethanol. $\mathrm{N}-\mathrm{H}$ stretching frequency shows a red-shift due to $\mathrm{NH} / \pi$ and $\mathrm{N}-\mathrm{H}--\mathrm{O}$ bonding interaction. Aromatic $\mathrm{C}-\mathrm{C}$ and $\mathrm{C}-\mathrm{H}$ stretching frequency shift in the polar environment indicating that strength of $\pi-\pi$ interaction gets enhanced in the polar environment.

Both, theoretical and experimental results show that in the BA-ethanol-benzene mixture, different kinds of interactions are presented. The strength of these interactions varies with concentration. At lower 
concentration $\left(\mathrm{x}_{1}=0.0\right)$, weak $\mathrm{OH} / \pi$ interaction between benzene and ethanol take place while at other mole fraction $\mathrm{N}-\mathrm{H}--\mathrm{O}, \mathrm{O}-\mathrm{H}--\mathrm{N}, \mathrm{NH} / \pi$ interaction is present between unlike molecules.

\section{Declarations}

Acknowledgement: One of the authors is thankful to University Grant Commission (UGC), New Delhi for providing financial support under "CSIR-UGC SRF fellowship".

The FTIR instrument facility of Nanoscience \& Nanotechnology Centre, DSB campus Nainital-263002, India is gratefully acknowledged. A special thanks to Dr. Nanda Gopal Sahoo (Professor, In- charge PRSNanoscience \& Nanotechnology Centre, Department of Chemistry, Kumaun University, Nainital) for allowing the laboratory work and to Dr Lalit Mohan (Assistant Professor, Department of Chemistry, Kumaun University, Nainital) for his guidance and instrument handling.

Funding: University Grant Commission (UGC), New Delhi (CSIR-NET SRF).

Conflicts of interest/Competing interests: Authors had no conflict of interest.

Availability of data and material (data transparency): Supplementary file

Code availability: The open-source code programmes available for free download at the following address, are used for present work.

GAMMES: https://www.msg.chem.iastate.edu/gamess/

Avogadro: https://avogadro.cc/

ChemCraft: https://www.chemcraftprog.com/

\section{*Authors' contributions:}

The original ideas, image and data analysis, presentation of the finding, and writing was done by Hema. Dr. Tara Bhatt has supervised the work, helped in literature consultation, and editing of the paper. Pratibha Arya, Dr. Charu Ch. Dhondiyal, Himani Tiwari and Dr. Kamal Devlal helped in the interpretation of the study and writing.

\section{References}

1. Tomé LIN, Rosado MTS, Ermelinda M et al (2006) Molecular structure of mono-and 1,2aminoderivatives of cyclohexane: Steric strain effects as determining factors. https://doi.org/10.1016/j.theochem.2006.09.035

2. Nair UR, Sivabalan R, Gore GM et al (2005) Hexanitrohexaazaisowurtzitane (CL-20) and CL-20-based formulations (review). Combust Explos Shock Waves 41:121-132. https://doi.org/10.1007/s10573005-0014-2 
3. Whetsel KB, Roberson WE, Krell MW (1960) Solvent and Concentration Effects on the Near-Infrared N$\mathrm{H}$ Bands of Primary Aromatic Amines. Anal Chem 32:1281-1286.

https://doi.org/10.1021/ac60166a015

4. Lady JH, Whetsel KB (1964) Infrared Studies of Amine Complexes. I. Self-Association of Aniline in Cyclohexane Solution1. J Phys Chem 68:1001-1009. https://doi.org/10.1021/j100787a004

5. Whetsel KB, Lady JH (1965) Infrared Studies of Amine Complexes. III. Association of Aniline and NMethylaniline with Benzene, N,N-Dimethylaniline, Pyridine, and N,N-Dimethylcyclohexylamine1. J Phys Chem 69:1596-1602. https://doi.org/10.1021/j100889a025

6. Farmer VC, Thomson RH (1960) Inter- and intra-molecular hydrogen bonding in anilines. Spectrochim Acta 16:559-562. https://doi.org/https://doi.org/10.1016/0371-1951(60)80013-6

7. Mohammed Hussain SG, Kumar R, Mohamed Naseer Ali M, Kannappan V (2019) Structural effect on the strength of non-covalent interactions in binary mixtures of benzyl amine and certain ethers through ultrasonic, FT-IR spectral and DFT studies at 303.15 K. J Mol Liq 277:865-875. https://doi.org/10.1016/j.molliq.2019.01.015

8. Meyer EA, Castellano RK, Diederich F (2003) Interactions with Aromatic Rings in Chemical and Biological Recognition. Angew Chemie Int Ed 42:1210-1250. https://doi.org/https://doi.org/10.1002/anie.200390319

9. Sinnokrot MO, Sherrill CD (2006) High-Accuracy Quantum Mechanical Studies of $\pi-\pi$ Interactions in Benzene Dimers. J Phys Chem A 110:10656-10668. https://doi.org/10.1021/jp0610416

10. Sherrill CD (2013) Energy Component Analysis of $\pi$ Interactions. Acc Chem Res 46:1020-1028. https://doi.org/10.1021/ar3001124

11. The Sherrill Group: Notes. http://vergil.chemistry.gatech.edu/notes/index.html. Accessed 4 Feb 2021

12. Xu W, Sun Y, Dong $X$ et al (2017) Local order and vibrational coupling of the $C=0$ Stretching Mode of Y-Caprolactone in liquid binary mixtures. Sci Rep 7:12182. https://doi.org/10.1038/s41598-01712030-1

13. Pádua AAH, Costa Gomes MF, Canongia Lopes JNA (2007) Molecular Solutes in lonic Liquids: A Structural Perspective. Acc Chem Res 40:1087-1096. https://doi.org/10.1021/ar700050q

14. Kamieńska-Piotrowicz E, Dziewulska K, Stangret J (2010) An Effective Method for Studying Intermolecular Interactions in Binary Liquids with Hydrogen Bonds; FTIR Spectra and Ab Initio Calculations in the N-Methylformamide - Methanol System. J Phys Chem B 114:5810-5818. https://doi.org/10.1021/jp911530d

15. Jacinto FSF, Siqueira LJA, Alves WA (2009) FT-Raman, FTIR and density functional theory studies of a hydrogen-bonded formamide:pyridine complex. J Raman Spectrosc 40:1585-1590. https://doi.org/https://doi.org/10.1002/jrs.2303

16. Zhou Y, Wang Z, Gong S et al (2018) Comparative study of hydrogen bonding interactions between Nmethylacetamide and Methyl Acetate/Ethyl Formate. J Mol Struct 1173:321-327. https://doi.org/10.1016/j.molstruc.2018.07.012 
17. Kannan PP, Karthick NK, Arivazhagan G (2020) Hydrogen bond interactions in the binary solutions of formamide with methanol: FTIR spectroscopic and theoretical studies. Spectrochim Acta - Part A Mol Biomol Spectrosc 229:117892. https://doi.org/10.1016/j.saa.2019.117892

18. Belton DJ, Plowright R, Kaplan DL, Perry CC (2018) A robust spectroscopic method for the determination of protein conformational composition - Application to the annealing of silk. Acta Biomater 73:355-364. https://doi.org/10.1016/j.actbio.2018.03.058

19. Stackhouse S, Stixrude L (2010) Theoretical Methods for Calculating the Lattice Thermal Conductivity of Minerals. Rev Mineral Geochemistry 71:253-269. https://doi.org/10.2138/rmg.2010.71.12

20. Cheng J, Kang C, Zhu W et al (2003) N-Methylformamide - Benzene Complex as a Prototypical Peptide $\mathrm{N}-\mathrm{H} \cdots \pi$ Hydrogen-Bonded System: Density Functional Theory and MP2 Studies. J Org Chem 68:7490-7495. https://doi.org/10.1021/jo026910b

21. Gordon MS, Schmidt MW (2005) Advances in electronic structure theory: GAMESS a decade later. In: Theory and Applications of Computational Chemistry. Elsevier, pp 1167-1189

22. Perri MJ, Weber SH (2014) Web-Based Job Submission Interface for the GAMESS Computational Chemistry Program. J Chem Educ 91:2206-2208. https://doi.org/10.1021/ed5004228

23. Chai J-D, Head-Gordon M (2008) Long-range corrected hybrid density functionals with damped atomatom dispersion corrections. Phys Chem Chem Phys 10:6615-6620.

https://doi.org/10.1039/B810189B

24. Waller M, Grimme S (2016) In: Leszczynski J (ed) Weak Intermolecular Interactions: A Supermolecular Approach BT - Handbook of Computational Chemistry. Springer Netherlands, Dordrecht, pp 1-27

25. Hema BT (2021) Study of molecular interaction in a ternary liquid mixture of $n$-hexane, ethanol and benzene. Mater Today Proc. https://doi.org/10.1016/J.MATPR.2021.04.264

26. Zaitseva KV, Varfolomeev MA, Solomonov BN (2012) Thermodynamic functions of hydrogen bonding of amines in methanol derived from solution calorimetry data and headspace analysis. Thermochim Acta 535:8-16. https://doi.org/10.1016/j.tca.2012.02.005

27. Hobza P, Havlas Z (2000) Blue-Shifting Hydrogen Bonds. Chem Rev 100:4253-4264. https://doi.org/10.1021/cr990050q

28. Kumar RM, Elango M, Parthasarathi R et al (2012) The role of C-H... $\pi$ interaction in the stabilization of benzene and adamantane clusters. J Chem Sci 124:193-202. https://doi.org/10.1007/s12039-0120218-4

29. Barth A (2007) Infrared spectroscopy of proteins. Biochim Biophys Acta - Bioenerg 1767:1073-1101. https://doi.org/10.1016/j.bbabio.2007.06.004

30. Zhu B, Li J, He Y et al (2003) Thermal and infrared spectroscopic studies on hydrogen-bonding interaction of biodegradable poly(3-hydroxybutyrate)s with natural polyphenol catechin. Green Chem 5:580-586. https://doi.org/10.1039/b304708c

31. Ghoraishi MS, Hawk JE, Phani A et al (2016) Clustering mechanism of ethanol- water mixtures investigated with photothermal microfluidic cantilever deflection spectroscopy. Nat Publ Gr 1-7. https://doi.org/10.1038/srep23966 
32. Bader JS, Berne BJ (1994) Quantum and classical relaxation rates from classical simulations. J Chem Phys 100:8359-8366. https:// doi.org/10.1063/1.466780

33. Ramírez R, López-Ciudad T, Kumar PP, Marx D (2004) Quantum corrections to classical timecorrelation functions: Hydrogen bonding and anharmonic floppy modes. J Chem Phys 121:39733983. https://doi.org/10.1063/1.1774986

34. Raju K (2015) FTIR studies of hydrogen bonding interaction between the hydroxyl and carbonyl liquids. 6:44-52

35. Answer Key for Infrared Assignment Fall (2014) http://www.chem.ucla.edu/ bacher/General/30BL/problems/spectroscopy/assignmentF15/key.html. Accessed 26 May 2021

36. Plyler EK (1952) Infrared Spectra of Methanol, Ethanol, and n-Propanol

37. NYQUIST R (2001) Benzene and Its Derivatives. In: Interpreting Infrared, Raman, and Nuclear Magnetic Resonance Spectra. Elsevier, pp 351-423

38. Reichenbächer M, Popp J (2012) In: Reichenbächer M, Popp J (eds) Vibrational Spectroscopy BT Challenges in Molecular Structure Determination. Springer Berlin Heidelberg, Berlin, pp 63-143

39. Arunan E, Desiraju GR, Klein RA et al (2011) Definition of the hydrogen bond (IUPAC Recommendations 2011). Pure Appl Chem 83:1637-1641. https://doi.org/10.1351/PAC-REC-10-01-02

40. Vibhu I, Misra A, Gupta M, Shukla JP (2004) Ultrasonic and infrared study of molecular interactions in ternary mixtures of 1-naphthol and 2-naphthol with 2-propanone in benzene. Pramana 62:1147. https://doi.org/10.1007/BF02705261

41. Rajpurohit AS, Rajesh R, Muhamed RR et al (2019) DFT investigation of role of $\mathrm{N}-\mathrm{H} \cdots \mathrm{O}$ and $\mathrm{N}-\mathrm{H} \cdots \pi$ interactions in the stabilization of the hydrogen bonded complexes of anisole with aromatic amines. Heliyon 5:e02155-e02155. https://doi.org/10.1016/j.heliyon.2019.e02155

42. Raja PMV, Barron AR (2019) Physical methods in chemistry and nano science. Open Stax 366-367

43. Martinez CR, Iverson BL (2012) Rethinking the term "pi-stacking". Chem Sci 3:2191-2201. https://doi.org/10.1039/C2SC20045G

44. Li AY, Ji HB, Cao LJ (2009) Theoretical study on effects of hydrogen bonding on the ring stretching modes of pyridine. J Chem Phys 131:164305. https://doi.org/10.1063/1.3251123

\section{Tables}

Table 1: Single point energy and dipole moment of monomer and dimer. Interaction energies of the complexes calculated by the Supermolecular method (geometries optimized by DFT/ B3LYP and interaction energies calculated on these optimized geometries by DFT/wB97X-D theory). 


\begin{tabular}{|lllll|}
\hline & energy(au) & $\Delta \mathrm{E}(\mathrm{au})$ & $\Delta \mathrm{E}(\mathrm{Kcal} / \mathrm{mol})$ & Dipole moment (D) \\
\hline Benzylamine & -326.8871912961 & & & 1.296 \\
\hline Ethanol & -155.0421486608 & & & 1.774 \\
\hline Benzene & -232.2233040759 & & & 0.000 \\
\hline BA-BA (I) & -653.7868039628 & -0.012421 & -7.795 & 1.948 \\
\hline BA-BA (II) & -653.7857246619 & -0.011342 & -7.117 & 0.667 \\
\hline BA-B & -559.1183893867 & -0.007894 & -4.954 & 1.404 \\
\hline BA-ETH & -481.9413852910 & -0.012045 & -7.559 & 0.585 \\
\hline Ba-eth-B & -714.1744453674 & -0.021801 & -13.681 & 2.665 \\
\hline
\end{tabular}

Table 2: The spectral peak and vibrational bands of pure components were taken from the literature.

\begin{tabular}{|c|c|c|c|c|c|}
\hline \multicolumn{2}{|c|}{ Benzylamine } & \multirow{2}{*}{$\begin{array}{c}\text { Ethanol } \\
\left(\mathrm{cm}^{-1}\right)\end{array}$} & \multirow[b]{2}{*}{ Band } & \multicolumn{2}{|l|}{ Benzene } \\
\hline$\left(\mathrm{cm}^{-1}\right)$ & Band & & & $\left(\mathrm{cm}^{-1}\right)$ & Band \\
\hline $\begin{array}{l}3290 \\
3373\end{array}$ & $\begin{array}{l}\mathrm{NH}_{2} \text { stretching (primary } \\
\text { amine) }\end{array}$ & $\begin{array}{l}3230- \\
3550\end{array}$ & OH stretching & 3099,3068 & $\mathrm{CH}$ stretching \\
\hline $\begin{array}{l}3027- \\
3106\end{array}$ & $\mathrm{CH}\left(\mathrm{sp}_{2}\right)$ stretching & 2961 & $\begin{array}{l}\mathrm{CH}\left(\mathrm{sp}_{2}\right) \\
\text { stretching }\end{array}$ & 3032 & $\mathrm{CH}$ stretching \\
\hline $\begin{array}{l}2368- \\
2920\end{array}$ & $\mathrm{CH}\left(\mathrm{sp}_{3}\right)$ stretching & 2927 & $\begin{array}{l}\mathrm{CH}\left(\mathrm{sp}_{3}\right) \\
\text { stretching }\end{array}$ & $\begin{array}{l}1506,1614 \\
1465\end{array}$ & CC stretching \\
\hline 1605 & $\mathrm{NH}_{2}$ bending & $\begin{array}{l}1102 \\
1055\end{array}$ & CO stretching & 1086,1035 & $\begin{array}{l}\text { In plane } \mathrm{CH} \\
\text { bending }\end{array}$ \\
\hline $\begin{array}{l}1496 \\
1605\end{array}$ & $\begin{array}{l}\mathrm{C}=\mathrm{C} \text { stretching } \\
\text { (aromatic) }\end{array}$ & & & 738 & $\begin{array}{l}\text { oop } \mathrm{CH} \\
\text { bending }\end{array}$ \\
\hline 1454 & $\mathrm{CH}_{2}$ bending & & & & \\
\hline 1026 & CN stretching & & & & \\
\hline $\begin{array}{l}698 \\
739\end{array}$ & Oop (out of plane) & & & & \\
\hline
\end{tabular}

Table 3: FTIR spectra peak(s) details of wavenumber range $3550-3100 \mathrm{~cm}^{-1}$ 


\begin{tabular}{|lcccccc|}
\hline \multicolumn{7}{|c|}{ Peak(s) $\left(\mathbf{3 5 5 0 - 3 0 0 0} \mathbf{c m}^{-1}\right)$} \\
\hline System & $\mathbf{( \mathbf { c m } ^ { - 1 } )}$ & $\mathbf{T}(\%)$ & $\mathbf{( \mathbf { c m } ^ { - 1 } )}$ & $\mathbf{T}(\%)$ & $\left(\mathbf{c m}^{-1}\right)$ & $\mathbf{T}(\%)$ \\
\hline BA & 3371.10 & 94.53 & 3284.83 & 95.61 & - & - \\
\hline Ethanol & 3308.63 & 75.97 & - & - & - & - \\
\hline Benzene & - & - & - & - & - & - \\
\hline 0.6 & 3359.57 & 89.77 & 3285.74 & 88.96 & 3177.21 & 89.94 \\
\hline 0.5 & 3361.38 & 92.06 & 3285.41 & 90.80 & 3172.51 & 91.89 \\
\hline 0.4 & 3359.57 & 90.32 & 3286.69 & 89.90 & 3177.54 & 91.35 \\
\hline 0.3 & 3360.97 & 90.17 & 3292.25 & 89.99 & 3180.43 & 91.70 \\
\hline 0.2 & 3361.38 & 90.82 & 3300.16 & 90.87 & - & - \\
\hline 0.1 & 3362.69 & 90.64 & 3299.50 & 90.70 & - & - \\
\hline 0.0 & 3324.93 & 90.57 & - & - & - & - \\
\hline
\end{tabular}

Table 4: FTIR spectra peak(s) details of wavenumber range $3100-2900 \mathrm{~cm}^{-1}$

\begin{tabular}{|lcccccc|}
\hline \multicolumn{7}{|c|}{ Peak(s) $\left(\mathbf{3 1 0 0 - 2 9 0 0 \mathbf { ~ c m } ^ { - 1 } )}\right.$} \\
\hline System & $\mathbf{( \mathbf { c m } ^ { - 1 } )}$ & $\mathbf{T}(\%)$ & $\mathbf{( \mathbf { c m } ^ { - 1 } )}$ & $\mathbf{T}(\%)$ & $\left(\mathbf{c m}^{-1}\right)$ & $\mathbf{T}(\%)$ \\
\hline BA & 3026.06 & 88.54 & - & - & 2911.54 & 93.41 \\
\hline Ethanol & - & - & 2973.24 & 71.37 & 2928.46 & 85.79 \\
\hline Benzene & 3035.86 & 80.08 & - & - & - & - \\
\hline 0.6 & 3028.26 & 88.82 & 2968.33 & 83.85 & 2918.23 & 87.28 \\
\hline 0.5 & 3028.57 & 91.45 & 2968.33 & 85.79 & 2922.07 & 88.75 \\
\hline 0.4 & 3033.68 & 89.10 & 2969.60 & 84.0 & 2921.76 & 89.45 \\
\hline 0.3 & 3034.44 & 88.70 & 2969.60 & 84.55 & 2921.11 & 90.54 \\
\hline 0.2 & 3035.84 & 87.96 & 2970.56 & 85.25 & 2920.46 & 91.39 \\
\hline 0.1 & 3036.15 & 86.94 & 2971.83 & 85.33 & 2923.99 & 92.01 \\
\hline 0.0 & 3036.75 & 87.34 & 2973.10 & 87.52 & - & - \\
\hline
\end{tabular}

Table 5: FTIR spectra peak(s) details of wavenumber range $1490-1465 \mathrm{~cm}^{-1}$ 


\begin{tabular}{|lll|}
\hline & \multicolumn{2}{l|}{ Peak(s) $\left(1490-1465 \mathbf{~ c m}^{-1}\right)$} \\
\hline System & $\left(\mathbf{c m}^{-1}\right)$ & T (\%) \\
\hline BA & - & - \\
\hline Ethanol & - & - \\
\hline Benzene & 1478.24 & 80.26 \\
\hline 0.6 & - & - \\
\hline 0.5 & 1479.23 & 94.23 \\
\hline 0.4 & 1479.79 & 84.74 \\
\hline 0.3 & 1479.23 & 82.21 \\
\hline 0.2 & 1479.23 & 76.73 \\
\hline 0.1 & 1478.96 & 75.65 \\
\hline 0.0 & 1478.96 & 70.40 \\
\hline
\end{tabular}

Figures

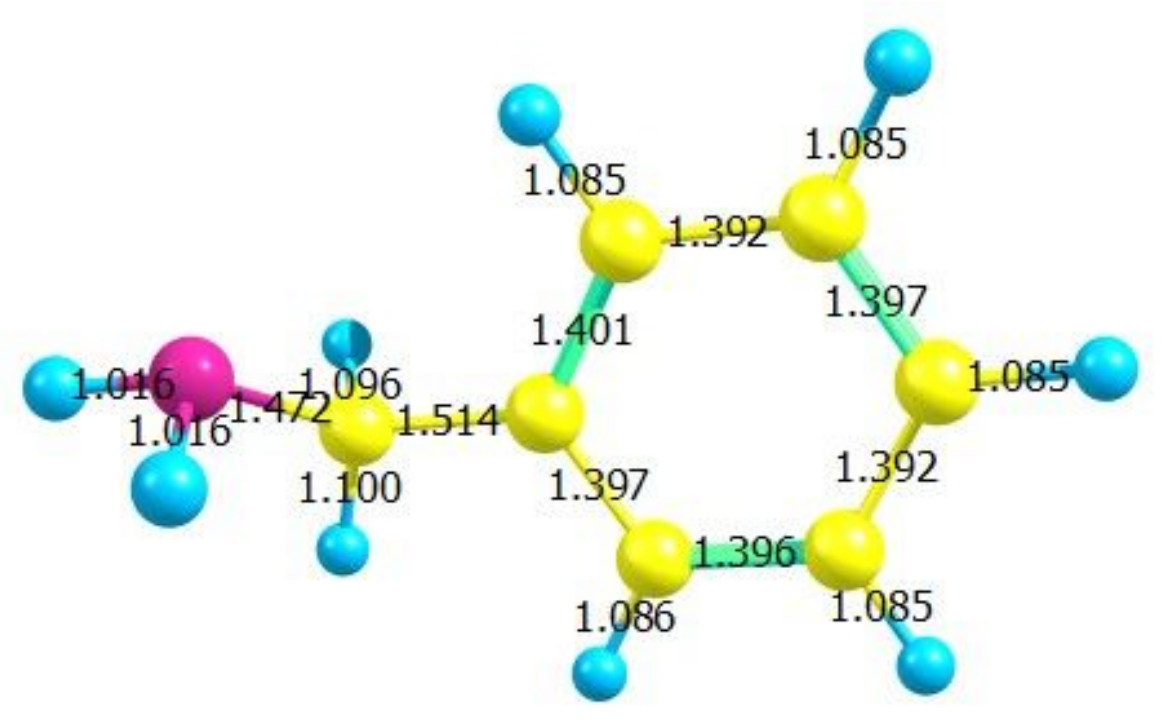

Figure 1

Structure of BA (distances in $\AA$ ) 


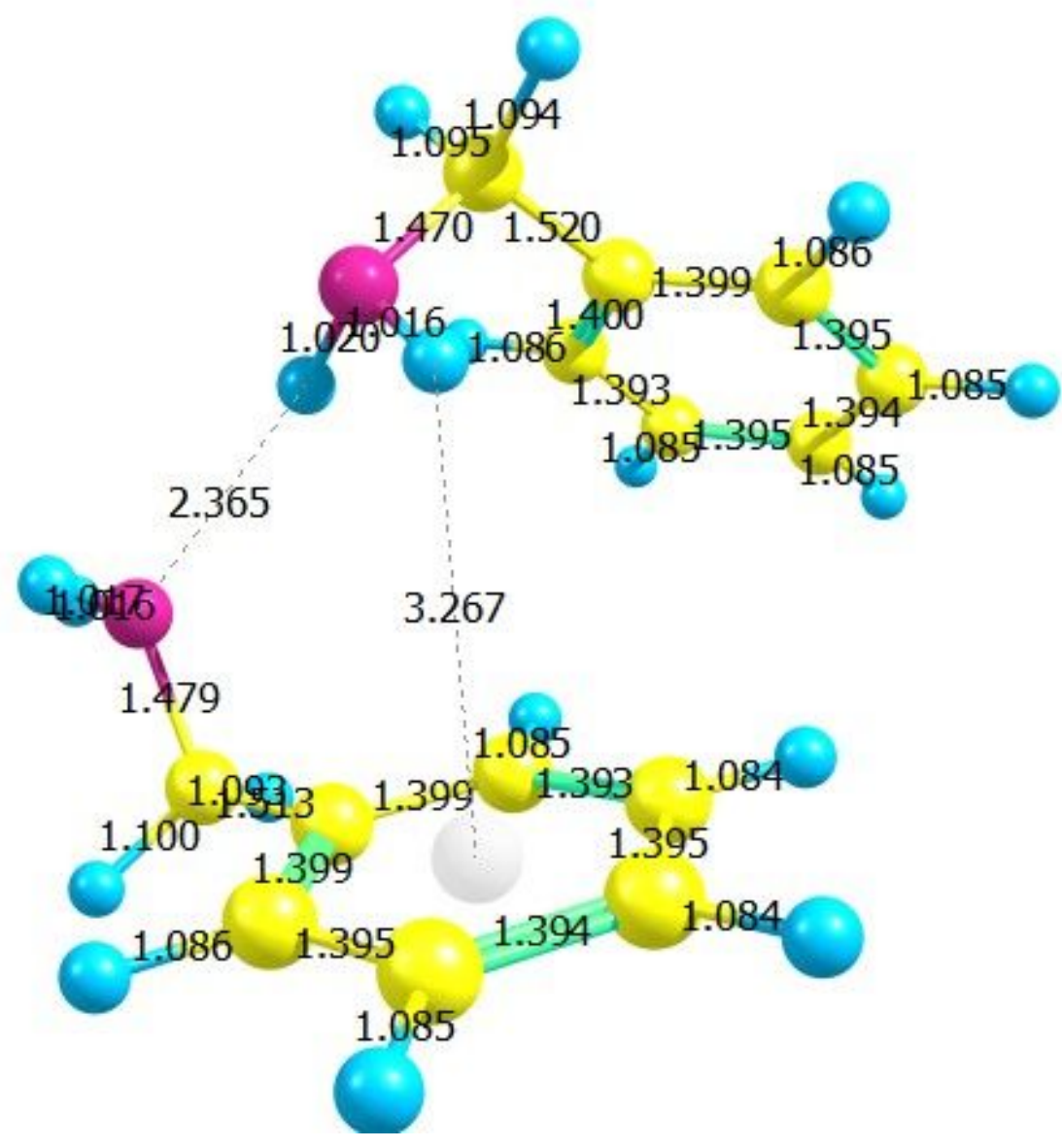

Figure 2

Structure of BA dimer (I) (distances in $\AA$ ) 


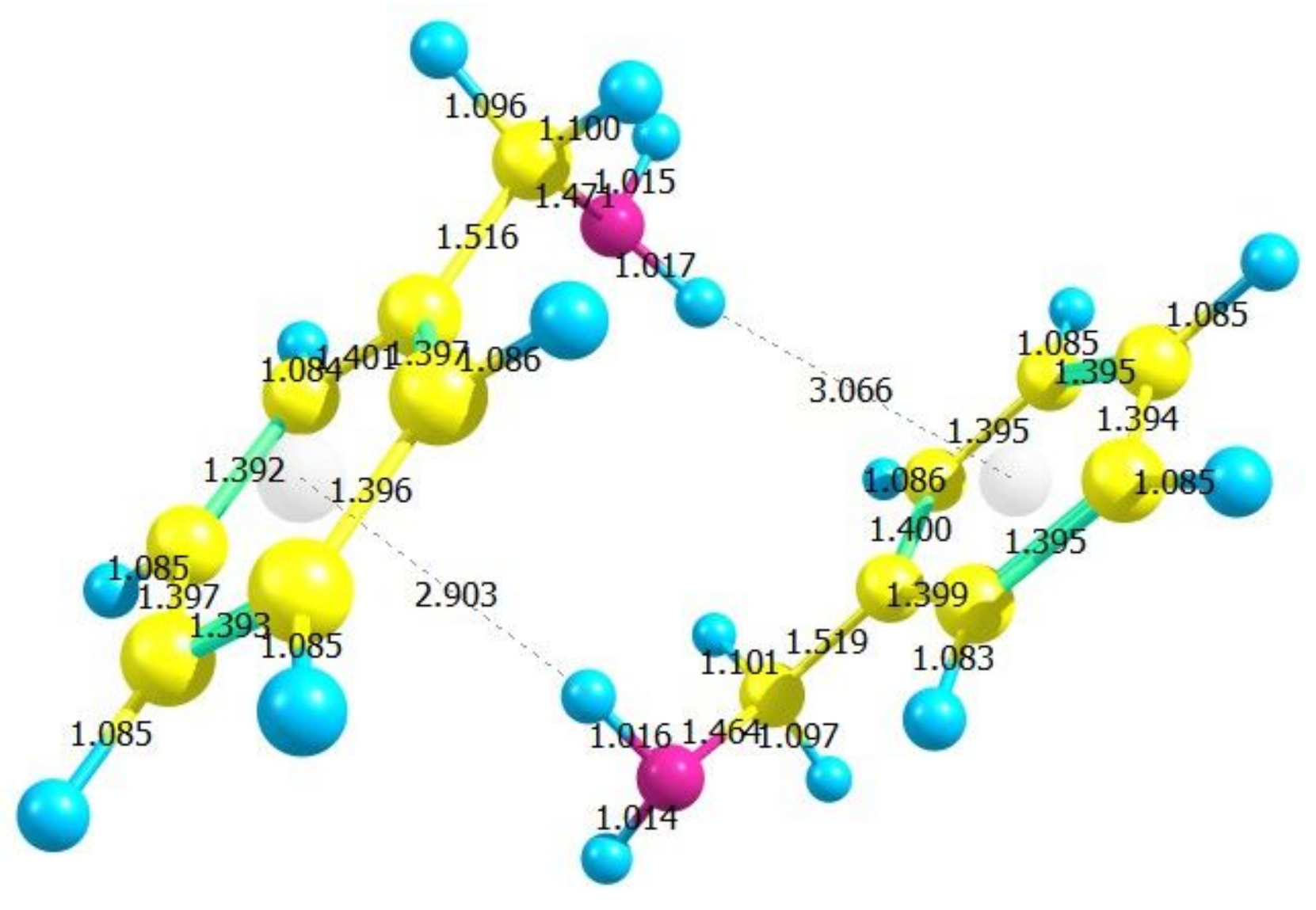

Figure 3

Structure of BA dimer (II) (distances in $\AA$ )

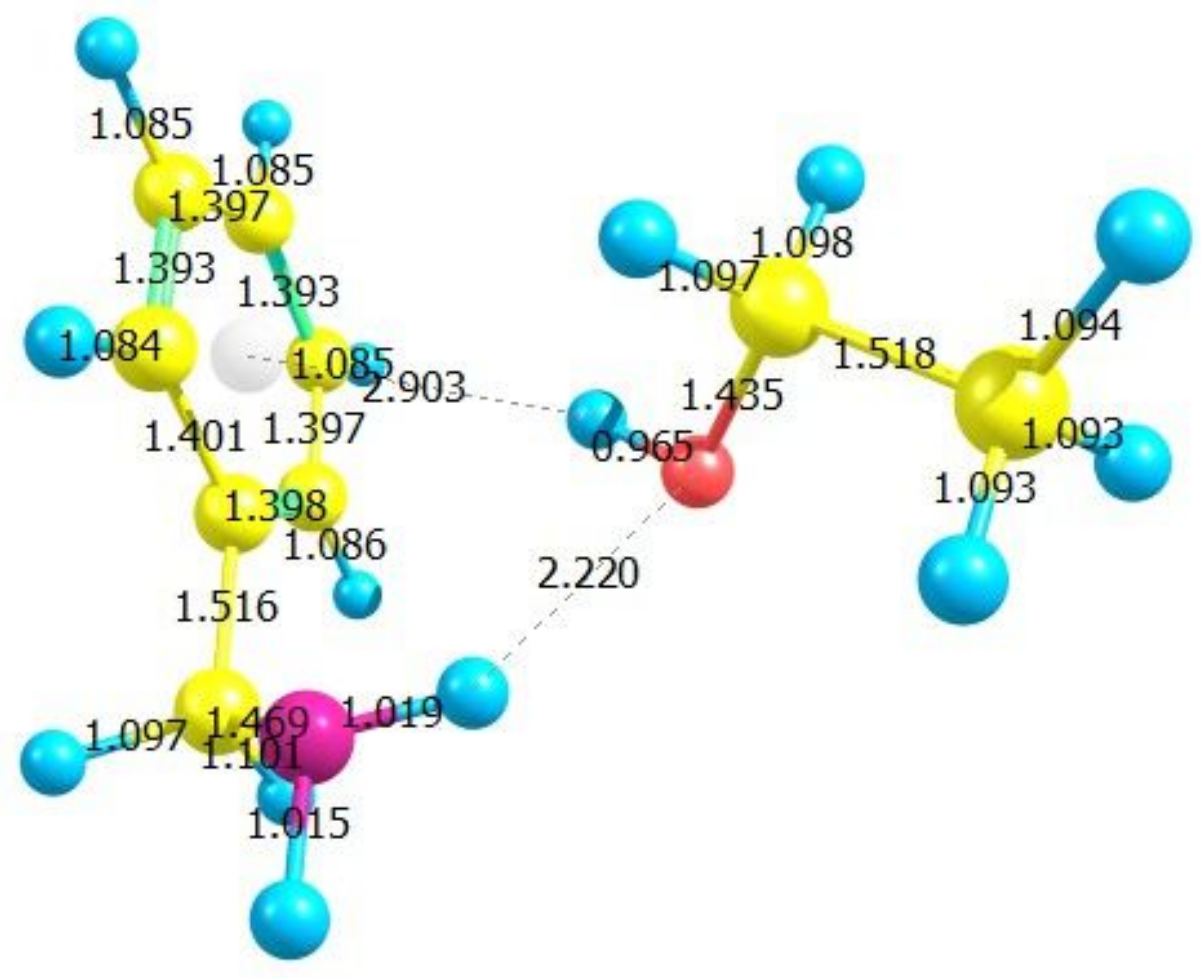

Figure 4 
Structure of BA-ethanol complex (distances in $\AA$ )

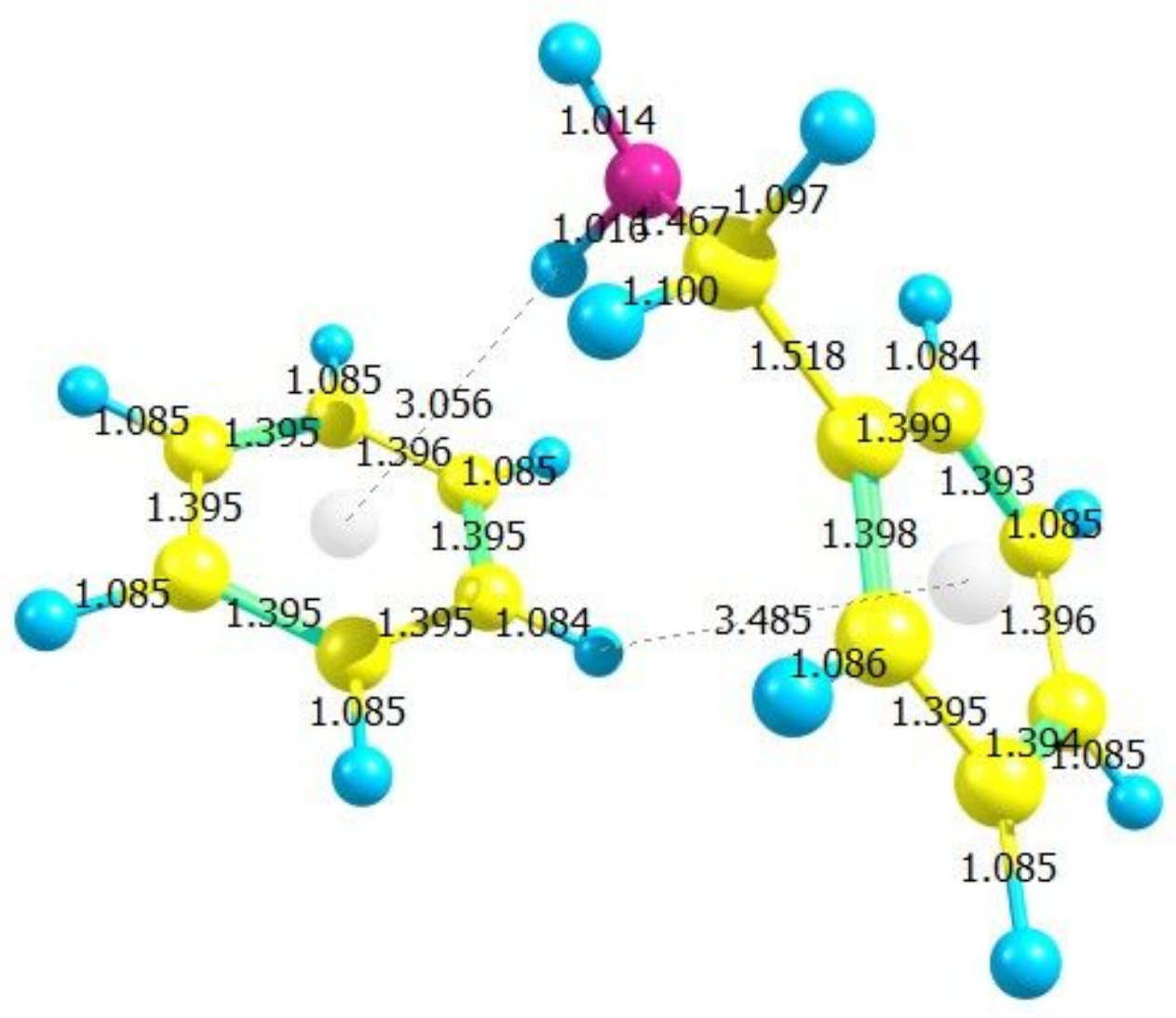

\section{Figure 5}

Structure of BA-benzene complex (distances in $\AA$ ) 


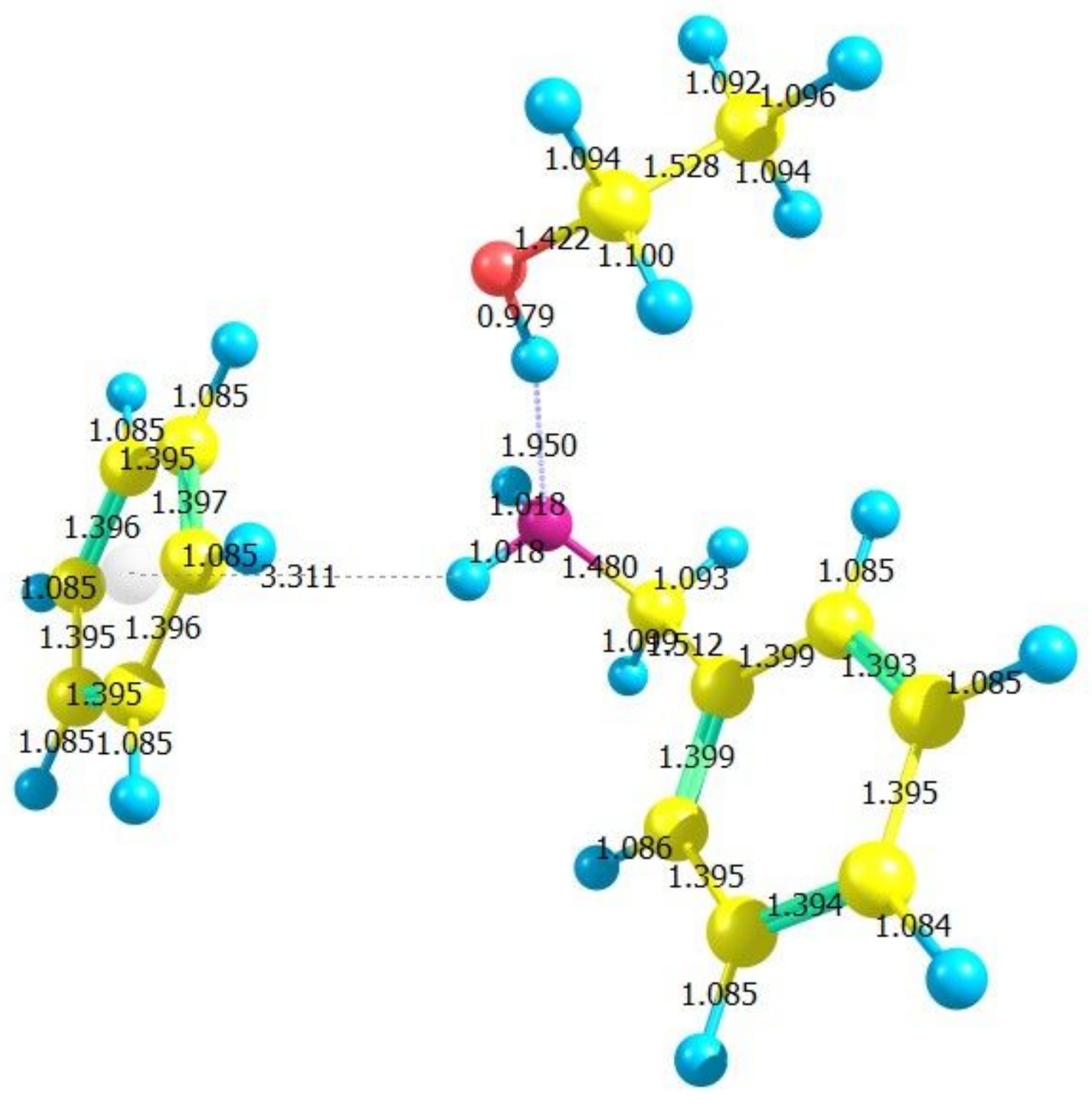

Figure 6

Structure of BA-ethanol-benzene complex (distances in $\AA$ ) 


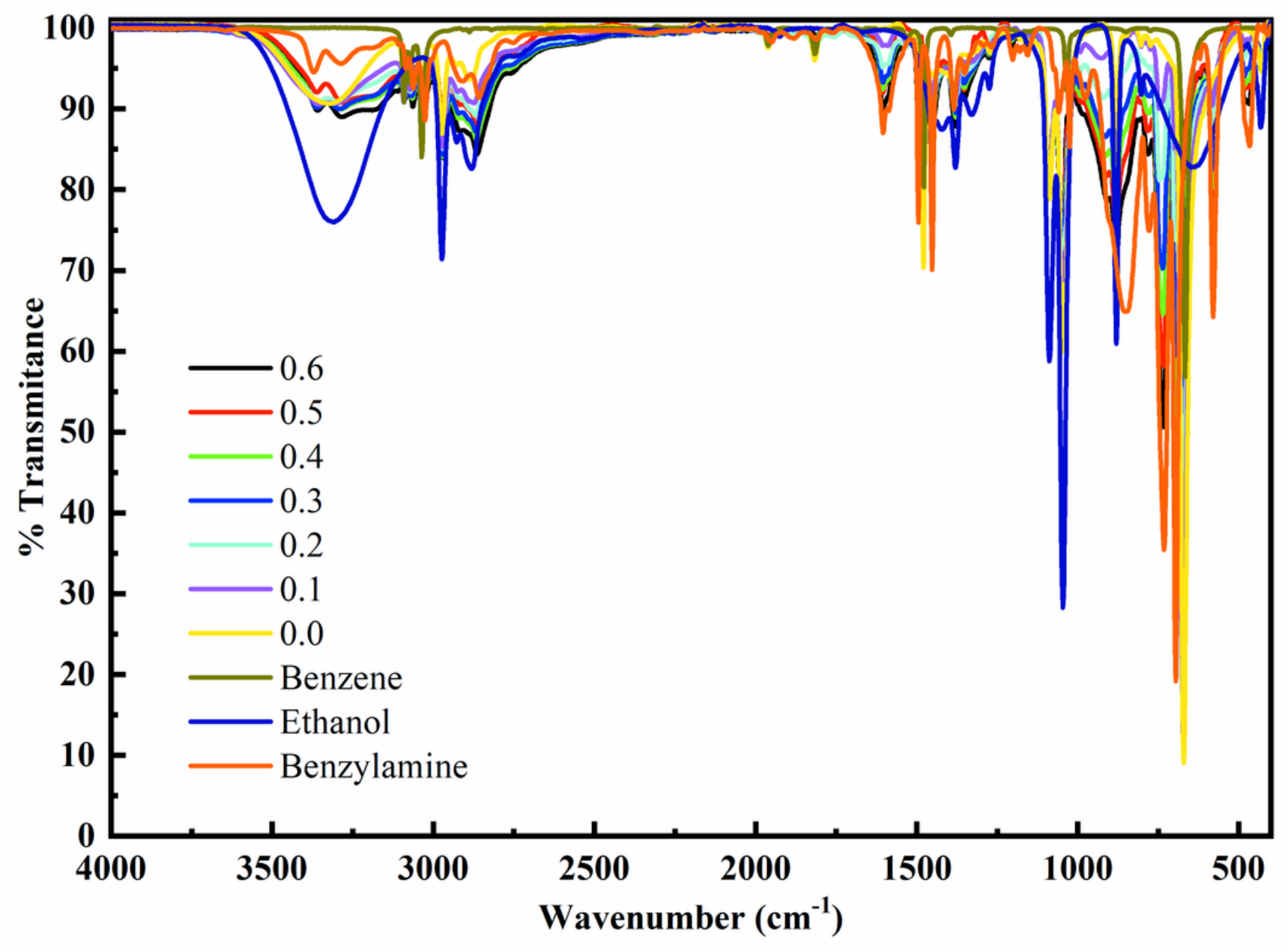

Figure 7

FTIR spectra of benzylamine, ethanol, benzene and their mixture at different concentrations. 


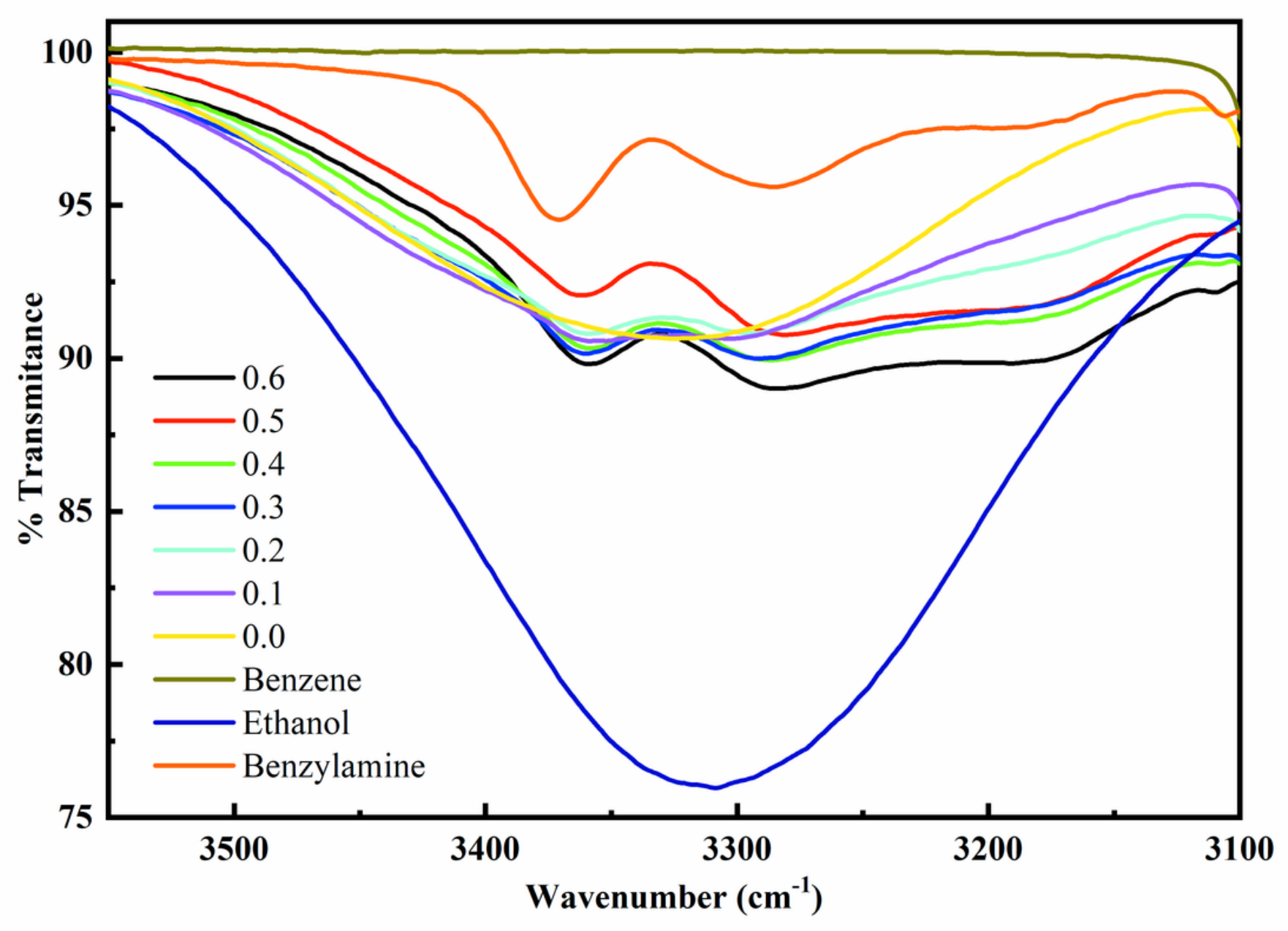

Figure 8

FTIR spectra (3550-3100 cm-1 wavelength range) of benzylamine, ethanol, benzene and their mixture at different concentration. 


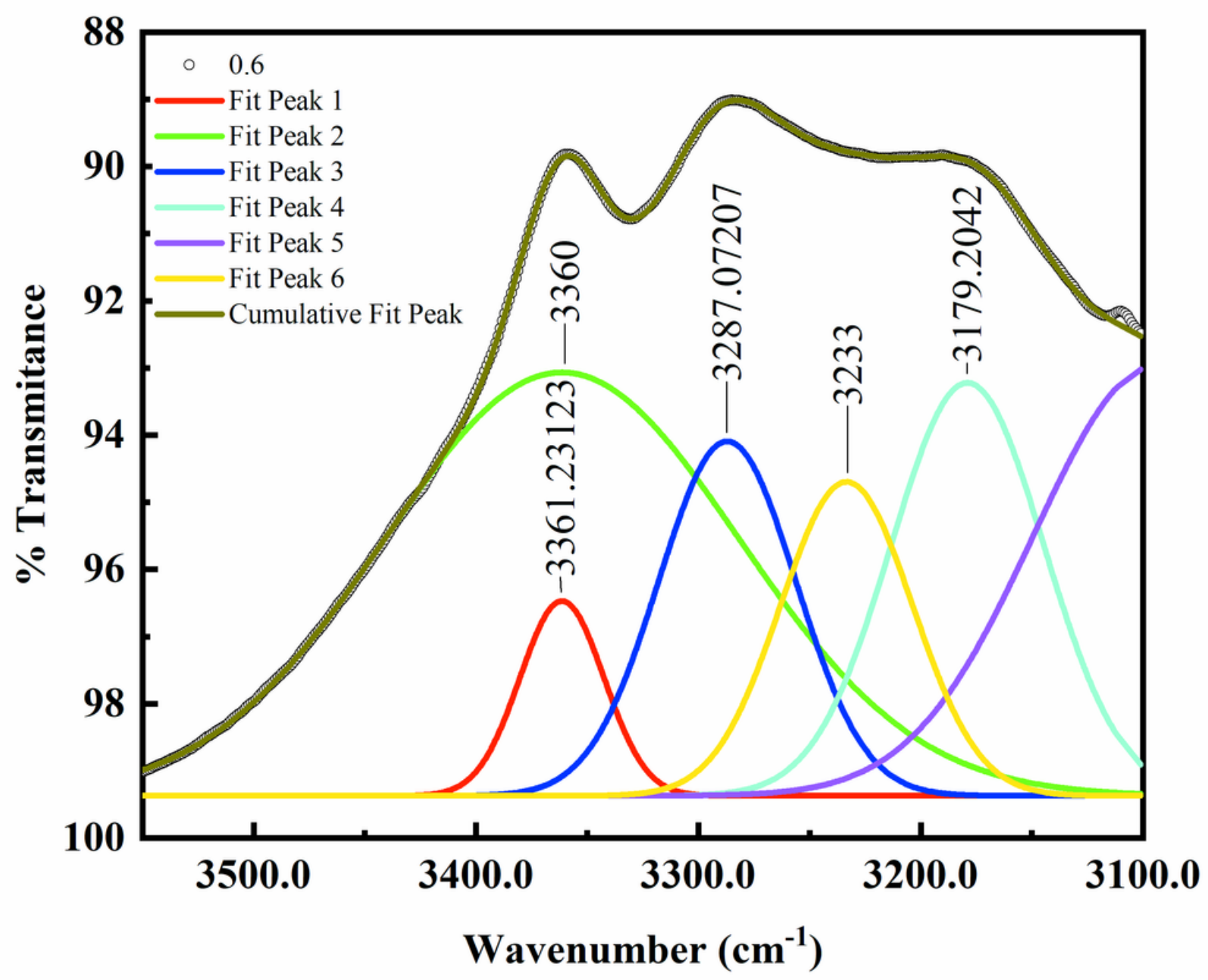

Figure 9

For $x 1=0.6$, deconvolution of the peak of the range $3550-3120 \mathrm{~cm}-1$. 


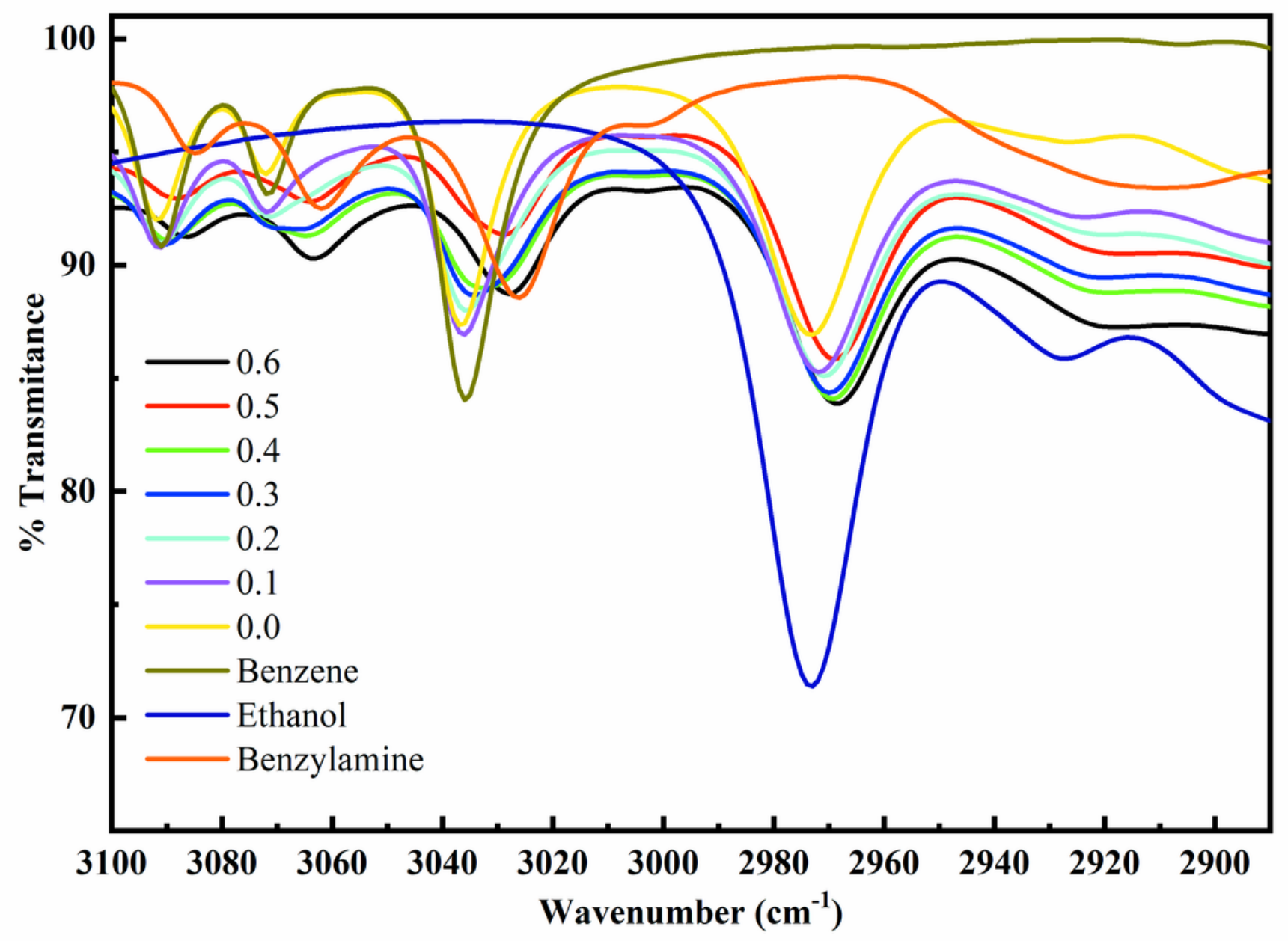

Figure 10

FTIR spectra (3100-2900 cm-1 range) of BA, ethanol, benzene and their mixture at different concentration. 


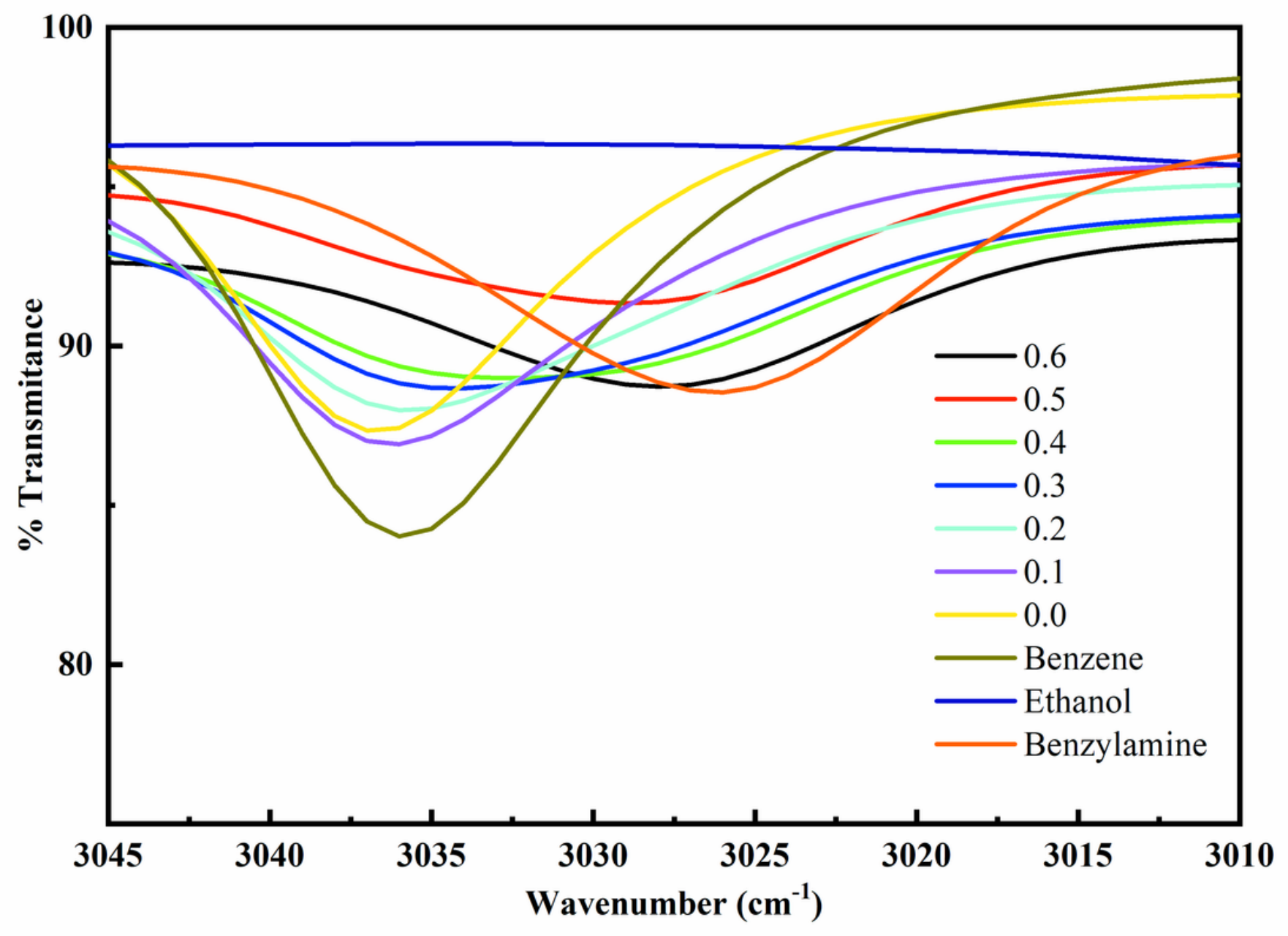

Figure 11

The spectra of the range $3010-3045 \mathrm{~cm}-1$. 


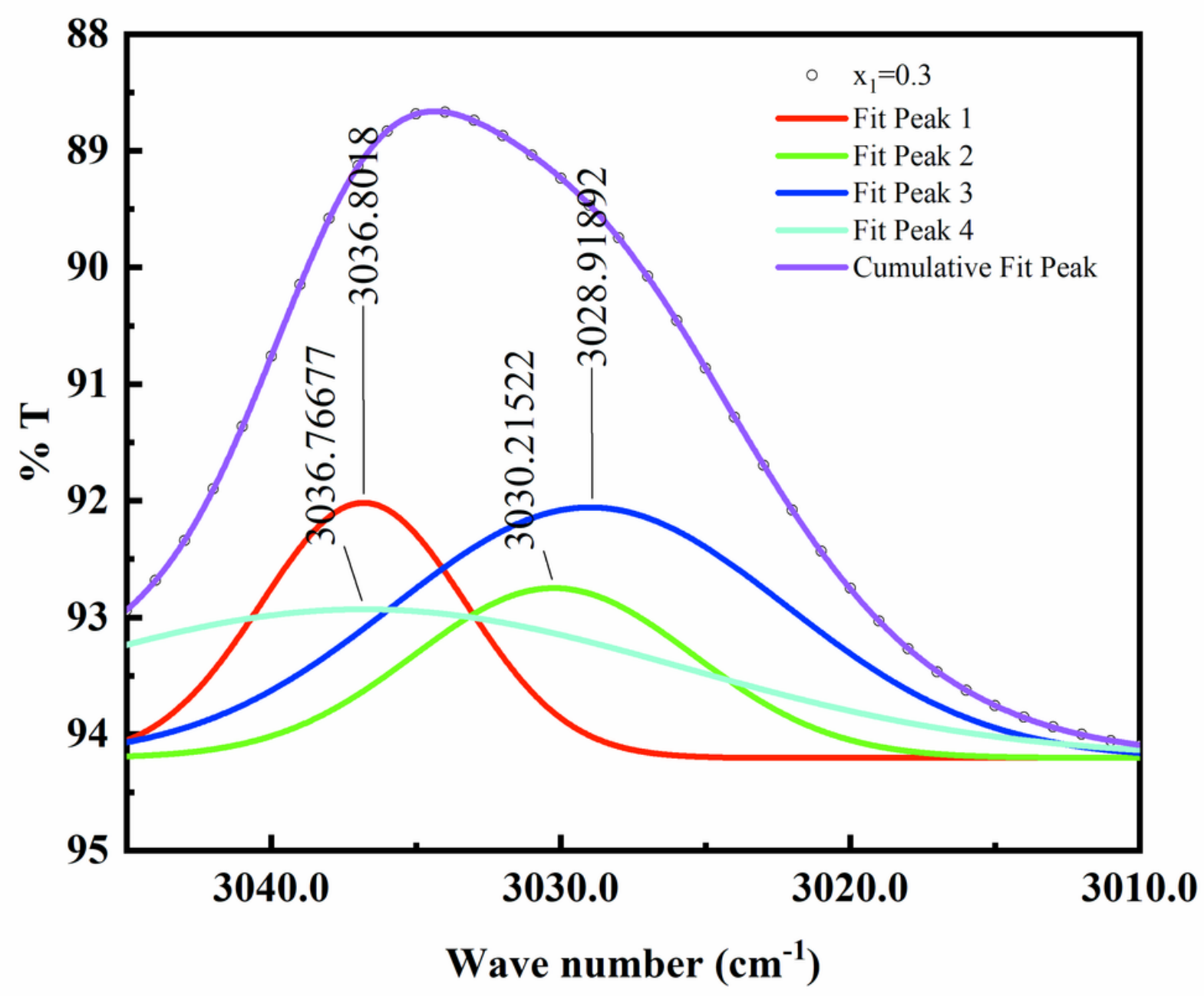

Figure 12

For $\mathrm{x} 1=0.3$, deconvolution of the peak of the range $3010-3045 \mathrm{~cm}-1$. 


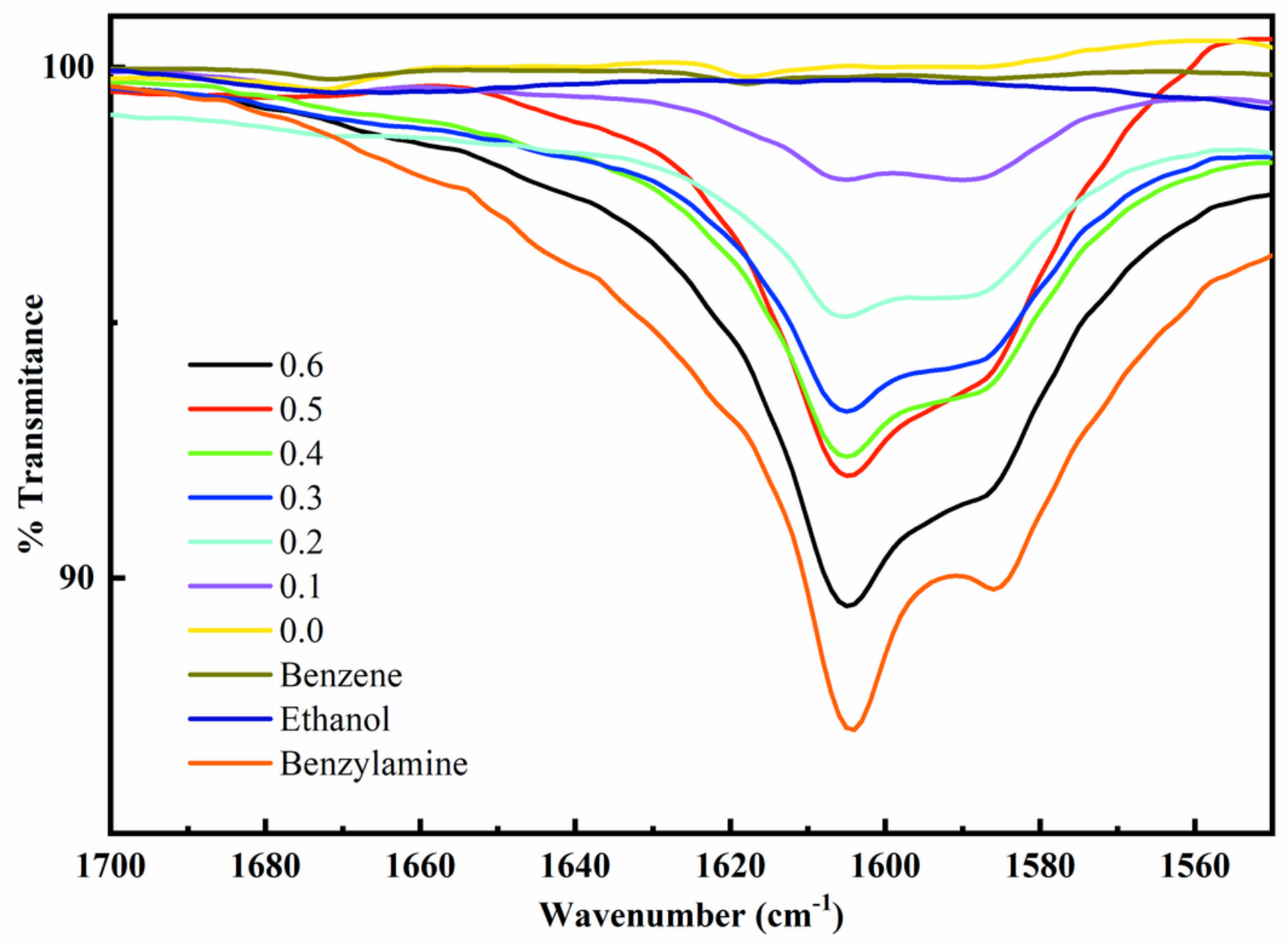

Figure 13

FTIR spectra (1700-1550 cm-1 range) of BA, ethanol, benzene and their mixture at different concentration. 


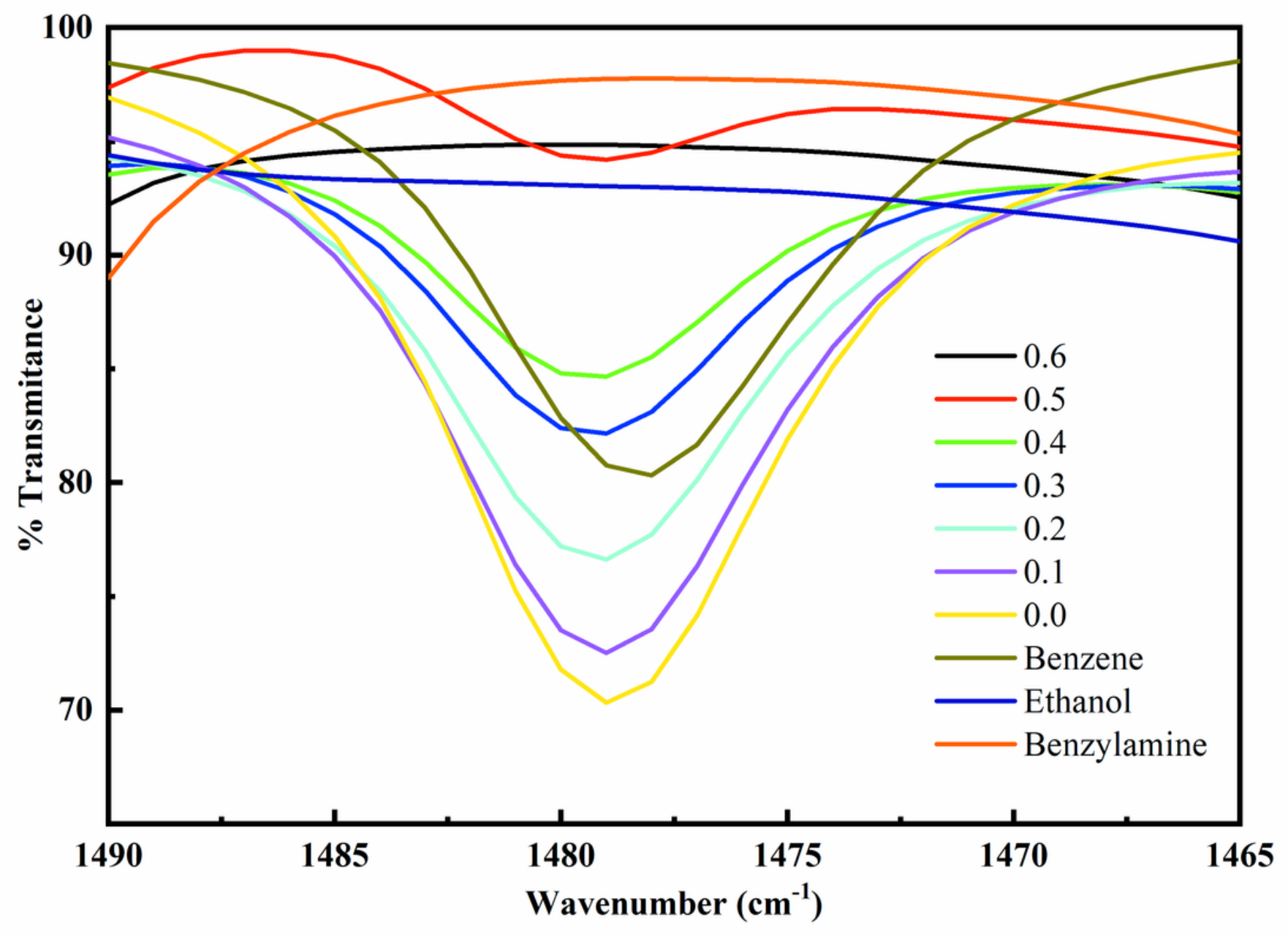

Figure 14

FTIR spectra (1490-1465 cm-1 wavelength range) of benzylamine, ethanol, benzene and their mixture at different concentration. 


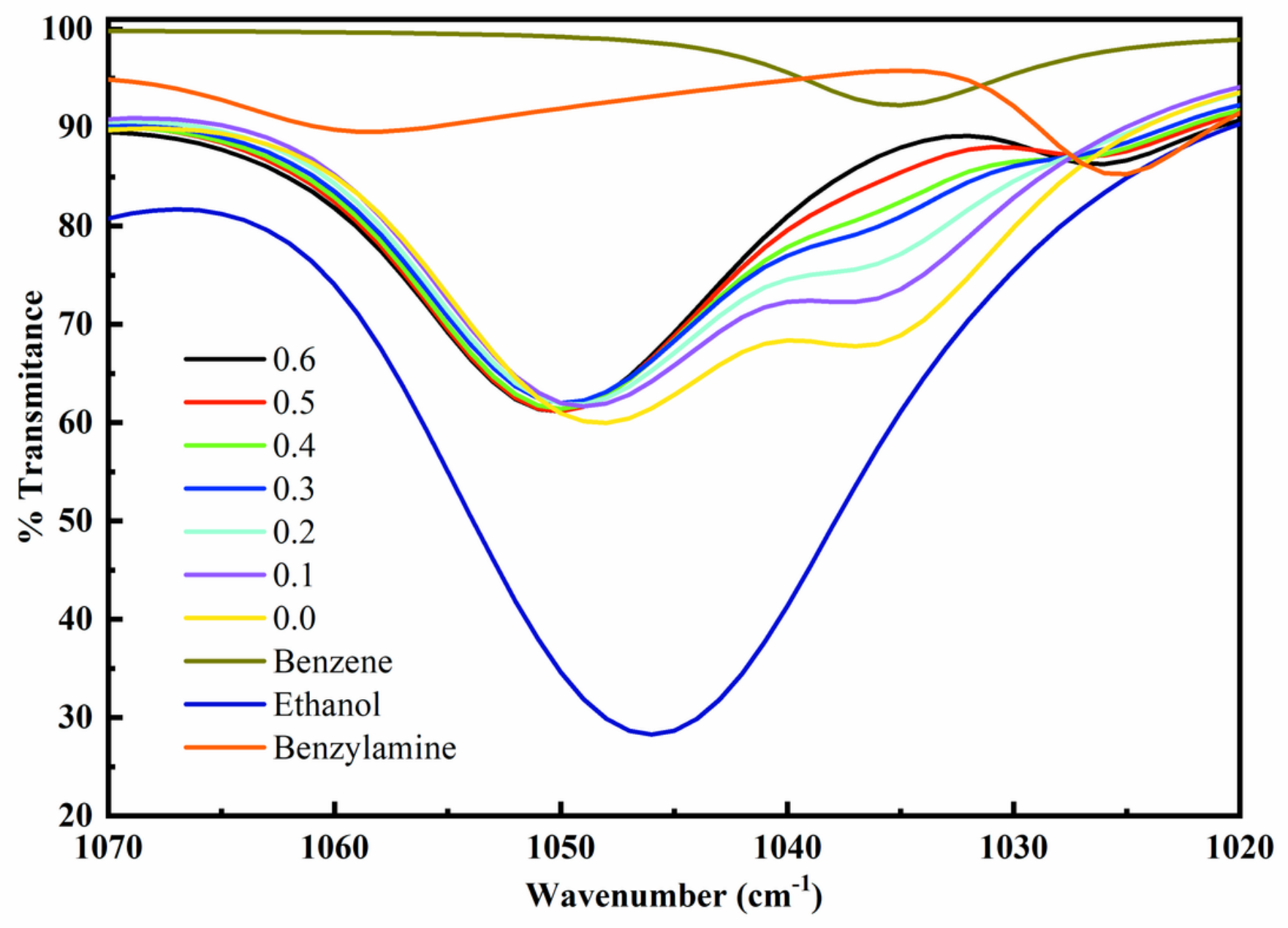

Figure 15

FTIR spectra (1070-1020 cm-1 wavelength range) of benzylamine, ethanol, benzene and their mixture at different concentration.

\section{Supplementary Files}

This is a list of supplementary files associated with this preprint. Click to download.

- suppportinginfo.docx 